
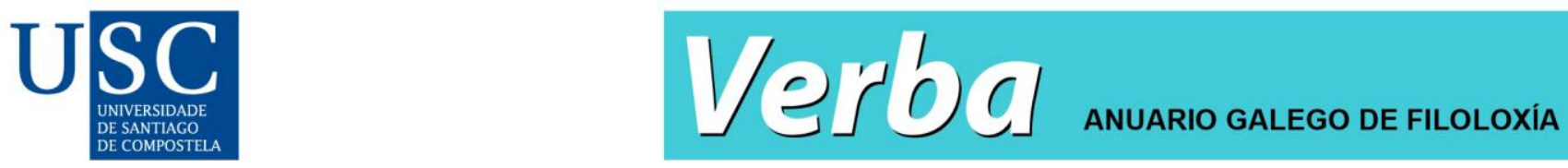

Verba: Anuario Galego de Filoloxía, 48, 2021. ISSN: 2174-4017

https://doi.org/10.15304/verba.48.6439

Artículos

\title{
La parasíntesis como manifestación de una lingüística del habla
}

Parasynthesis as a manifestation of linguistic perfomance

Luis González García ${ }^{1}$

1 Universidade da Coruña / Grupo HISPANIA, España

Recibido: 05/12/2019; Aceptado: 14/02/2020

\section{Resumen}

En este trabajo intentaremos demostrar que, aunque la parasíntesis no es propiamente un procedimiento para crear palabras en español, sí existen palabras parasintéticas. Para aclarar esta aparente paradoja examinaremos, en primer lugar, los distintos tipos de palabras analizadas generalmente como parasintéticas. Desechadas aquellas que se pueden justificar a partir de otros procedimientos de formación (esencialmente prefijación y morfo discontinuo) comprobaremos que las palabras que propiamente podemos denominar parasintéticas se justifican en el marco de una lingüística del habla (Saussure) o de la actuación (Chomsky) más adecuadamente que dentro del sistema de reglas de formación de palabras (RFP) del español, que vienen a infringir.

Palabras clave: español, morfología léxica, formación de palabras, parasíntesis.

\section{Abstract}

In this paper I will try to demonstrate that, although parasynthesis is not really a word formation procedure in Spanish, there are parasynthetic words. To clarify this apparent paradox, I will first examine the different types of words generally considered parasynthetic. After discarding those that can be explained through other formation procedures (essentially prefixing and discontinuous morphemes) I will argue that parasynthetic words can be accounted for more adequately within a linguistic approach to parole (Saussure) or performance (Chomsky) than within the system of Spanish Word Formation Rules (WFR), which they apparently infringe.

Keywords: Spanish, lexical morphology, word formation, parasynthesis. 


\section{INTRODUCCIÓN}

El estudio de la parasíntesis en español ha experimentado en los últimos años un considerable desarrollo. No podremos decir un extraordinario desarrollo porque, enfrentada con los procedimientos de formación de palabras prototípicos, siempre se ha considerado en cierta medida un recurso periférico o marginal.

La abundante bibliografía, más o menos reciente (se inicia en Lázaro Mora 1986 y Alcoba Rueda 1987), muy actualizada en Serrano-Dolader (2016, 2017), no ha conseguido acotar con precisión qué se entiende por parasíntesis. Más bien al contrario. Si, por ejemplo, analizamos la reciente propuesta de Serrano-Dolader (2017), el mayor especialista de la materia en español, observaremos que amplía el concepto a formas tradicionalmente consideradas compuestas (abrelatas, sacacorchos) o derivadas (caramelizar), al tiempo que niega carácter parasintético a formaciones que, de acuerdo con la interpretación tradicional, formarían parte del modelo prototípico (pordiosero, sietemesino, etc.). Otros autores limitan su extensión a las formaciones verbales (Martínez-Arbelaiz 2001, Varela Ortega 2005: 34) o a la parasíntesis por composición (González Ollé \& Casado Velarde 1992: 106, González Vergara 1999), cuando no la suprimen como procedimiento formador de palabras, integrada en la prefijación (Lázaro Mora 1986: 234-235, Blanco Rodríguez 1993: 431) o en la derivación (Montero Curiel 1999: 73).

Por tal motivo, para delimitar con precisión el alcance de la parasíntesis, organizaremos nuestra exposición dando cuenta de todos los tipos de construcciones morfológicas generalmente integradas bajo ese epígrafe. El análisis individualizado de cada una de esas clases de formaciones nos permitirá determinar las características peculiares de cada grupo, así como las comunes, con lo que estaremos en disposición de confrontar esta heterogénea categoría con los demás procedimientos de formación de palabras en español.

Señalan con acierto González Ollé \& Casado Velarde (1992: 94) que "La FP constituye uno de los ámbitos lingüísticos donde con mayor frecuencia y dificultad de interpretación se entrecruzan sincronía y diacronía", hasta el punto de que a menudo "pone al descubierto la discrepancia entre el análisis diacrónico y el sincrónico". Dado que nuestro propósito es analizar procesos de formación de palabras, la perspectiva diacrónica tendrá prioridad por cuanto intentaremos llegar, en la medida de lo posible, al momento en que cada proceso particular tuvo lugar. Veamos esto con un sencillo ejemplo: en uno de los apartados de este trabajo (§ 4.3.1) analizaremos la formación del adjetivo supersónico/a. Si consultamos la última edición del diccionario académico (DLE 2014), comprobaremos la existencia de las entradas sónico, ca y supersónico, ca, lo que nos permitiría postular, desde una perspectiva sincrónica, la actuación de un proceso derivativo regular sónico > supersónico. Nuestra argumentación para defender su carácter parasintético solo podrá asentarse, por tanto, en la constatación documental de que históricamente supersónico/a precede en el tiempo a sónico/a. Adoptar esta perspectiva diacrónica no es, sin embargo, incompatible con el estudio sincrónico. En realidad, lo que hacemos en casos como el mencionado es retrotraernos a una sincronía anterior. En este sentido hacemos nuestras las afirmaciones de Coseriu: "La lengua es siempre «sincrónica» en el sentido de que funciona sincrónicamente" (Coseriu 1978: 282), "la antinomia sincronía-diacronía no pertenece al plano del objeto sino al plano de la investigación: no se refiere al lenguaje, sino a la lingüística" (Coseriu 1978: 14).

Para finalizar esta introducción, debemos señalar que el marco teórico desde el que enfocamos este trabajo es el del funcionalismo europeo tal como está expuesto en González García (1997 y 
2019a). El funcionalismo, como es bien sabido (Rojo 1994), no deja de ser un conjunto heterogéneo de corrientes lingüísticas cuyo fundamento radica en la constatación de que las lenguas son instrumentos de comunicación. En este marco, intentaremos demostrar que es justamente la necesidad comunicativa la que determina la creación de las formaciones parasintéticas, la que está en el origen de unas formaciones ciertamente anómalas. Los principios hjemslevianos de no contradicción, exhaustividad y simplicidad estarán también presentes en la metodología de esta aportación.

\section{LAS FORMACIONES PARASINTÉTICAS EN SU HISTORIA}

El origen y la evolución del concepto de parasíntesis (y de formación parasintética) son bien conocidos (Heyna 2012, Richard 2017, Serrano-Dolader 2017, etc.), desde su génesis en la gramática clásica (Dionisio de Tracia) hasta Arsène Darmesteter, en el marco de la lingüística histórica del último cuarto del siglo XIX, con el que se asienta el término en su valor actual.

Estos trabajos nos muestran que el primitivo tecnicismo acuñado por Dionisio de Tracia ( $\pi \alpha \rho \alpha \sigma u ́ v \theta \varepsilon \tau o v)$ fue creado para denominar las palabras derivadas de un compuesto, lo que el

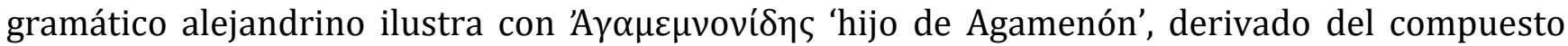

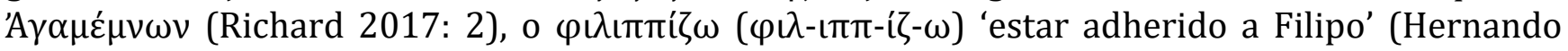
Cuadrado 1999: 79).

Con todo, y a pesar de algunos antecedentes, la formulación clásica de la parasíntesis se debe a Darmesteter ${ }^{1}$. En él se encuentra ya una definición y clasificación de los principales tipos de parasintéticos:

Soit barque et embarquer: le français ne possède ni le substantif embarque, ni le verbe barquer, il suffit cependant du rapprochement, de la synthèse du préfixe em et du suffixe er avec le radical barque pour qu'il en sorte immédiatement le verbe embarquer. Entrecolonne n'existe pas, ni colonnement, il suffit cependant de la synthèse du préfixe entre et du suffixe ment avec le radical colonne pour produire le composé [entrecolonnement].

Ces sortes de composés, où préfixes et suffixes se combinent avec le radical, ont reçu le nom de parasynthetiques, du grec para indiquant juxtaposition et de synthetique: ce terme exprime bien une formation où trois éléments juxtaposés concourent, par voie de synthèse, à la formation d'un mot nouveau (Darmesteter 1895: 23).

En esta cita, y en otras similares que se suceden en la producción del gramático francés ${ }^{2}$, se aprecian claramente las características que definirán la parasíntesis en los años sucesivos:

a) Son formaciones parasintéticas aquellas en las que se aplican simultáneamente (y no sucesivamente) los procedimientos de la composición y la derivación ${ }^{3}$. Debe tenerse en cuenta que los prefijos en esos comienzos de la morfología se asociaban con las preposiciones y los adverbios, por lo que en casos como embarquer se hablaba con propiedad de composición ${ }^{4}$. Sin embargo, como es bien sabido, más tarde los prefijos, vista su semejanza funcional con otros afijos, pasaron a formar parte de la derivación (Serrano-Dolader 2013: 815). En consecuencia, la definición de parasíntesis se ha adaptado para poder aplicarse a ese tipo de unidades. Se dirá, así, que la parasíntesis consiste en la prefijación y sufijación simultáneas. 
Como en la tradición gramatical también se documentan parasintéticos formados propiamente por composición y derivación simultáneas, podemos concluir que en la lingüística española bajo la etiqueta parasíntesis se identifican dos clases de creaciones:

i) Las formadas por composición y derivación simultánea (o parasíntesis por composición, Serrano-Dolader 1995), según los modelos ropavejero o mileurista.

ii) Las creadas por prefijación y sufijación simultáneas (o parasíntesis por afijación, SerranoDolader 1995), según los modelos envejecer o desalmado.

b) La segunda característica definitoria de los parasintéticos, la ramificación ternaria, se deriva directamente de la anterior. Si los dos procesos (composición-derivación, prefijaciónsufijación) son simultáneos y no sucesivos (3), automáticamente deja de ser operativa cualquier segmentación binaria, que necesariamente operaría sobre unidades no existentes (1)-(2):

(1) [[mil-eur] ista], implica *mileuro(s) > mileurista, es decir, se trataría de un derivado de un compuesto no existente (1a).

(2) [mil [eur-ista]], se corresponde con mil+*eurista, voz compuesta, uno de cuyos miembros es el derivado *eurista, no documentado (2a).

(3) [mil-eur-ista], como voz parasintética daría cuenta de una manera adecuada de los hechos empíricos (3a).

(1a) Palabra derivada

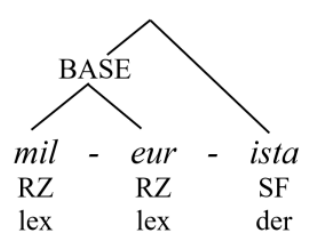

(2a) Palabra

compuesta

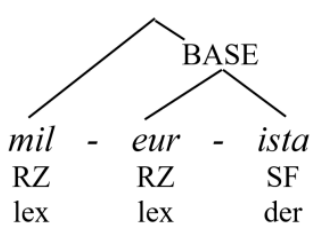

(3a) Palabra

parasintética

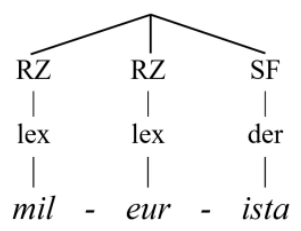

De la misma manera, envilecer no puede ser analizada como voz derivada por sufijación porque la base de derivación, *en-vil-, no se registra en español (1b). Tampoco es posible postular una prefijación (2b), dado que sucede lo mismo con la base sufijada, *vil-ec(e-r). De nuevo, el análisis parasintético ( $3 \mathrm{~b})$ daría cuenta satisfactoriamente de estos hechos. 
(1b) Palabra derivada (por sufijación)

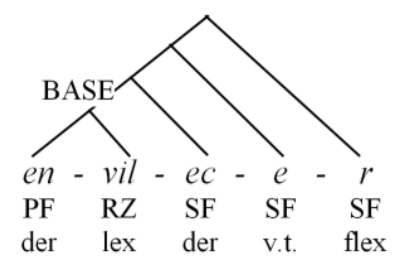

(2b) Palabra derivada (por prefijación

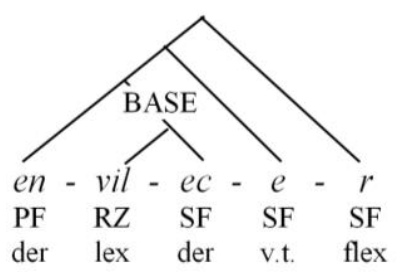

(3b) Palabra parasintética

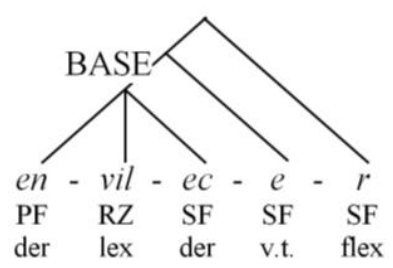

Desde distintos presupuestos se ha tratado de superar la anomalía que suponen las estructuras trimembres postulando etapas sucesivas de adjunción de prefijo o sufijo en verbos del tipo ensuciar, enflaquecer ([Pref [[X] Sf]], [[Pref [X]] Suf]), de manera poco convincente por cuanto no se ofrecen argumentos sólidos en favor de uno u otro análisis (Scalise 1984, 1994; Alcoba Rueda 1987; Pena Seijas 1991: 117-118; Haouet 2000: 44-67; Serrano-Dolader 2016: 18-20; Iacobini 2010: 2), o bien invocando la fusión de dos reglas de formación de palabras distintas (Bisetto \& Melloni 2008: 238-239) ${ }^{5}$.

Las implicaciones teóricas de la parasíntesis superan, con todo, las que acabamos de mencionar (simultaneidad de los procesos, operatividad de palabras no existentes, ramificaciones ternarias). Obsérvese que en ejemplos como embarquer o embarcar en propiedad no se identifican sufijos derivativos, pues -ar es muy discutible que se pueda integrar en esa categoría. Por otra parte, si embarcar no se analiza como un verbo simplemente derivado por prefijación es porque se considera que los prefijos derivativos no pueden cambiar la categoría de la base. Ello ha originado una controversia, todavía no resuelta, sobre la naturaleza de la vocal temática y de los morfemas flexivos en este proceso, sobre la existencia de morfos cero derivativos o sobre el papel de los prefijos en la derivación. Todas estas cuestiones están suficientemente tratadas en la bibliografía especializada (en Serrano-Dolader 2015, 2016 y 2017 se puede ver una completa panorámica de estas controversias por lo que en este trabajo solo aludiremos a ellas en aquellos apartados en que nos parezcan pertinentes).

La sucesiva adición de otros subtipos de formaciones parasintéticas dentro de los dos grandes bloques arriba mencionados provocará, por su parte, el planteamiento de nuevos problemas que los estudios morfológicos tratarán de identificar y solucionar. Por eso es importante que hagamos una relación de los subtipos de formaciones incluidas en los tratados sobre parasíntesis en español para analizar en cada caso cómo han sido abordadas todas esas cuestiones.

\section{CLASES DE FORMACIONES PARASINTÉTICAS EN ESPAÑOL}

Si analizamos la sección dedicada a la parasíntesis en los tratados de formación de palabras del español, podemos observar que hay una serie de voces que se repiten con asiduidad, dada la poca productividad de los principales tipos parasintéticos (sietemesino, ropavejero, misacantano, 
pordiosero...). Solo algunos esquemas (formaciones verbales que siguen los modelos envejecer, embarcar, ensuciar, aclarar...) tienen una productividad grande. Para organizar los datos partiremos de los cuadros 1 y 2 siguientes, en los que tratamos de ordenar en categorías homogéneas los distintos parasintéticos mencionados en cuatro obras que nos parecen representativas (Alemany Bolufer 1920, Casado Velarde 2015, Serrano-Dolader 1999, NGLE $2009)^{6}$.

Cuadro 1. Parasíntesis por afijación. Elaboración propia.

\begin{tabular}{|c|c|c|c|c|c|}
\hline \multicolumn{6}{|c|}{ Parasíntesis por prefijación y sufijación simultáneas } \\
\hline & $\begin{array}{c}1 \\
\text { embarcar }\end{array}$ & $\begin{array}{c}2 \\
\text { envejecer }\end{array}$ & $\begin{array}{c}3 \\
\text { submarino }\end{array}$ & $\begin{array}{c}4 \\
\text { desalmado }\end{array}$ & $\begin{array}{c}5 \\
\text { inalámbrico }\end{array}$ \\
\hline $\begin{array}{l}\text { Alemany } \\
\text { Bolufer } \\
(1920)\end{array}$ & $\begin{array}{l}\text { Endulzar } \\
\text { Aprisionar }\end{array}$ & & & Desalmado & \\
\hline $\begin{array}{l}\text { Casado } \\
\text { (2015) }\end{array}$ & & Entristecer & & & \\
\hline $\begin{array}{l}\text { NGLE } \\
\text { (2009) }\end{array}$ & $\begin{array}{l}\text { Aclarar, } \\
\text { Acercar, } \\
\text { Abotonar, } \\
\text { Ensuciar, } \\
\text { Embotellar, } \\
\text { Descabezar, } \\
\text { Refinar, } \\
\text { Reciclar }\end{array}$ & $\begin{array}{l}\text { Apedrear, } \\
\text { Anochecer, } \\
\text { Aterrizar, } \\
\text { Enseñorear, } \\
\text { Ensombrecer, } \\
\text { Encolerizar, } \\
\text { Reblandecer }\end{array}$ & & & \\
\hline $\begin{array}{l}\text { Serrano- } \\
\text { Dolader } \\
(1999)\end{array}$ & $\begin{array}{l}\text { Engordar, } \\
\text { Empeorar, } \\
\text { Aclarar, } \\
\text { Acortar, } \\
\text { Encarcelar, } \\
\text { Descarrilar, } \\
\text { Desterrar, } \\
\text { Despedazar, } \\
\text { Despiojar, } \\
\text { Condensar, } \\
\text { Entrecomillar, } \\
\text { Extravasar, } \\
\text { Refrescar, } \\
\text { Trasvasar, }\end{array}$ & $\begin{array}{l}\text { Ablandecer, } \\
\text { Empequeñecer } \\
\text { Atardecer, } \\
\text { Enfierecerse, }\end{array}$ & $\begin{array}{l}\text { Submarino } \\
\text { Antediluviano } \\
\text { Antigripal } \\
\text { Proclerical } \\
\text { Multicelular }\end{array}$ & $\begin{array}{l}\text { Afamado } \\
\text { Arrubiado } \\
\text { Ensotanado } \\
\text { Desalmado } \\
\text { Desvergonzado } \\
\text { Indoctrinado }\end{array}$ & $\begin{array}{l}\text { Amorfo } \\
\text { Apétalo } \\
\text { Inalámbrico } \\
\text { Indemne } \\
\text { Incoloro } \\
\text { Bicolor } \\
\text { Tetrasílabo }\end{array}$ \\
\hline
\end{tabular}


Cuadro 2. Parasíntesis por composición. Elaboración propia.

\begin{tabular}{|c|c|c|c|c|}
\hline \multicolumn{5}{|c|}{ Parasíntesis por composición y sufijación simultáneas } \\
\hline & $\begin{array}{c}6 \\
\text { pordiosero }\end{array}$ & $\begin{array}{c}7 \\
\text { cortoplacista }\end{array}$ & $\begin{array}{c}8 \\
\text { mileurista }\end{array}$ & $\begin{array}{c}9 \\
\text { machihembrar }\end{array}$ \\
\hline $\begin{array}{l}\text { Alemany } \\
\text { Bolufer } \\
\text { (1920) }\end{array}$ & & Treintaidoseno & $\begin{array}{l}\text { Picapedrero, Ropavejero, } \\
\text { Sietemesino, Misacantano }\end{array}$ & Machihembrar \\
\hline $\begin{array}{l}\text { Casado } \\
(2015)\end{array}$ & Ensimismamiento & $\begin{array}{l}\text { Cortoplacismo, } \\
\text { Cortoplacista, }\end{array}$ & $\begin{array}{l}\text { Misacantano, Picapedrero, } \\
\text { Ropavejero, Doceañista, } \\
\text { Mileurismo, Mileurista, } \\
\text { Milmillonario, Quinceañera, } \\
\text { Sietemesino, }\end{array}$ & \\
\hline $\begin{array}{l}\text { NGLE } \\
\text { (2009) }\end{array}$ & Pordiosero & & $\begin{array}{l}\text { Mileurista, Quinceañero, } \\
\text { Sietemesino, Tresañero, } \\
\text { Misacantano, Plenipotenciario, } \\
\text { Picapedrero, Ropavejero, } \\
\text { Vasodilatación, Vasodilatador. }\end{array}$ & Machihembrar \\
\hline $\begin{array}{l}\text { Serrano- } \\
\text { Dolader } \\
\text { (1999) }\end{array}$ & & & $\begin{array}{l}\text { Corchotaponero, Doceañista, } \\
\text { Misacantano, Venenosalival }\end{array}$ & $\begin{array}{l}\text { Machihembrar, } \\
\text { Mancornar, } \\
\text { Nordestear }\end{array}$ \\
\hline
\end{tabular}

Como se aprecia en los cuadros anteriores, hemos dispuesto las muestras de acuerdo con la oposición básica entre parasíntesis por afijación vs. parasíntesis por composición y, dentro de cada clase, hemos organizado en columnas los diferentes subtipos de voces incluidas bajo la etiqueta de parasíntesis, de acuerdo con el modelo lexicogenético que actúa en cada caso (hemos seleccionado para encabezar cada columna o subclase un ejemplo que nos parece significativo como representante del tipo).

Establecida la clasificación, procederemos ahora al análisis de cada una de dichas categorías.

\section{PARASÍNTESIS POR AFIJACIÓN}

Como se ha señalado con anterioridad, este procedimiento es el único realmente productivo en español, pues da lugar a una gran cantidad de verbos (verbos parasintéticos) y algunos adjetivos. Los modelos dominantes dentro de esta subclase de parasintéticos se pueden agrupar de la siguiente manera:

1) Modelo embarcar

2) Modelo envejecer 
3) Modelos submarino, desalmado, inalámbrico.

\subsection{Parasíntesis y prefijación}

Más arriba hemos indicado que numerosos verbos como fr. embarquer fueron incluidos por Darmesteter entre la clase prototípica de los parasintéticos. En castellano pertenecen a esta categoría los integrados en la columna 1 del cuadro 1 (modelo embarcar). Los prefijos más frecuentes en esta categoría son a-y en- (aclarar, agrandar, embarcar, engordar, ensuciar...), pero pueden aparecer muchos otros, como se aprecia en la mencionada columna (condensar, descabezar, refinar, trasvasar, etc.).

El carácter parasintético de estos verbos se basa en la inexistencia de las bases *embarco o *barcar, por lo que se postula la necesidad de un proceso formativo en el que se añaden simultáneamente a la base barco el prefijo en- y el sufijo -ar. Esta característica los diferenciaría de los verbos prefijados, cuya base es verbal: des-tapar (<tapar), des-enchufar, re-elaborar, etc.

El fundamento teórico en el que se basa el carácter parasintético de estas unidades se asienta en dos postulados controvertidos:

i) La imposibilidad por parte de los prefijos de cambiar la categoría de la base. Los derivados prefijales serían siempre de naturaleza homogénea (des-tapar, in-útil, re-pensar, prelatino...).

ii) El carácter derivativo de la desinencia verbal -ar o de la vocal temática - $a$.

Ambas aseveraciones han sido objeto de largo debate. Por nuestra parte intentaremos aportar algunos argumentos en contra de los dos postulados. Es de destacar que, en efecto, los sufijos derivativos pueden cambiar la categoría de la base con relativa frecuencia (aunque no

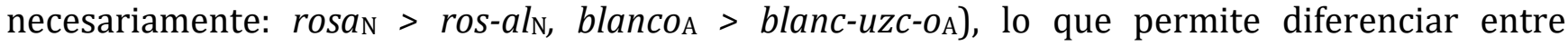
derivación heterogénea (elegirv > elegible $e_{\mathrm{A}}$ medir $>$ medición $n_{\mathrm{N}}$ ) y derivación homogénea (rosal, blancuzco). Frente a ellos, los prefijos mostrarían una incapacidad absoluta para cambiar la categoría de la base (la prefijación sería siempre homogénea) (Lázaro Mora 1986: 222, Felíu Arquiola 2003: 31, Varela Ortega 2005: 64, Serrano-Dolader 2017: 54).

La realidad lingüística, sin embargo, parece contradecir este aserto. Corbin (1980) fue quien con mayor ahínco defendió el carácter transcategorizador de los prefijos. En una línea diferente, desde distintas aproximaciones, se ha puesto de relieve el carácter heterogéneo de los prefijos. Así, en el marco generativo algunos autores han formalizado una distinción precisa entre prefijos externos o léxicos, de una parte, y, de otra, prefijos internos o funcionales (Felíu Arquiola 2003: 36-40), clasificación aplicada al español por Varela Ortega \& Haouet (2001) y Haouet (2000: 667-430). Aceptada esta oposición, basada en su distinto comportamiento, desde el punto de vista de una gramática funcional la explicación más adecuada para dar cuenta de los datos es la de considerar que los prefijos internos o funcionales (en-gordar, a-clarar) pueden cambiar la categoría de su base, al contrario que los externos: pre-renacimiento $(\mathrm{N}>\mathrm{N})$, pre-electoral $(\mathrm{A}>\mathrm{A})$, pre-ver $(\mathrm{V}>\mathrm{V})$.

En esa consideración que restringe la derivación heterogénea a la sufijación influye, sin duda, el hecho de que, por su posición final en el tema, los sufijos entran en contacto directo con los morfemas flexivos, también sufijales en castellano. Por dicho motivo, en muchos casos los 
morfemas derivativos nominalizadores se amalgaman con los flexivos (-ción asigna género femenino a los derivados deverbales; -ista, género común; -aje, masculino), lo que evidentemente incide en su carácter transcategorizador. Pero esta propiedad es, en cambio, desconocida por los sufijos verbalizadores, siempre seguidos de la vocal temática que precede a los morfemas flexivos. Aun así, en el caso de la derivación verbal es frecuente hablar de los sufijos -izar, -ecer, -ear, -ificar, etc. como si se tratara de una unidad morfológica, lo cual, evidentemente, es indefendible, como se aprecia en los siguientes análisis basados en el principio de conmutación:

(4) and-á-ba-mos

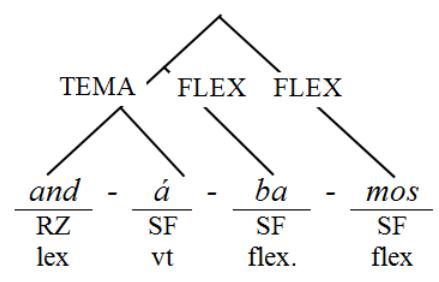

(5) enferm-á-ba-mos

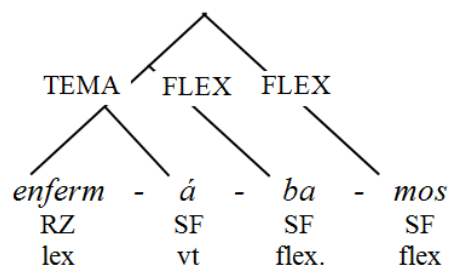

(6) vigor-iz-á-ba-mos

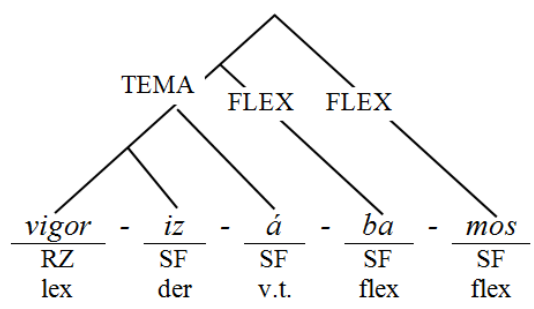

Los ejemplos anteriores nos muestran que un verbo simple primitivo (andábamos), un verbo derivado sin afijación (derivación inmediata, impropia o conversión: enfermábamos) o un derivado mediante sufijación (vigorizábamos) presentan idéntica distribución morfológica: tema acotado por la vocal temática, morfo modo-temporal, morfo de número y persona. La vocal temática marca de forma clara el límite entre el tema verbal y el constituyente flexivo externo al tema.

El caso que aquí nos interesa es el de los derivados verbales por sufijación (6) con objeto de poder contrastar sus propiedades en relación a los verbos prefijados. Obsérvese que en dicho tipo de verbos es general señalar que los sufijos -izar, -ecer, etc. (en realidad conglomerados morfológicos: -iz(ar) o, mejor, -iz-a-r) tienen la propiedad de formar verbos a partir de adjetivos o sustantivos. Es decir, son afijos dotados de la propiedad de generar derivación heterogénea, propiedad que se niega a los prefijos.

Sin embargo, un sucinto análisis de los verbos prefijados que aquí nos ocupan nos muestra un completo paralelismo en el comportamiento de los prefijos y sufijos verbalizadores ${ }^{7}$. Sus temas son idénticos (tema complejo o derivado):

(7) [en-gord-a]-r

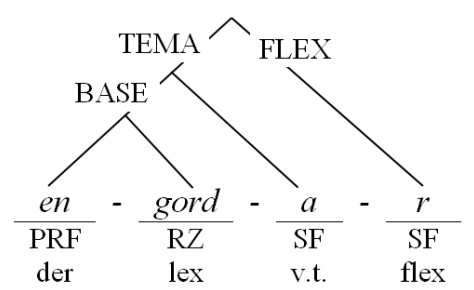

(6a) [vigor-iz-a]-r

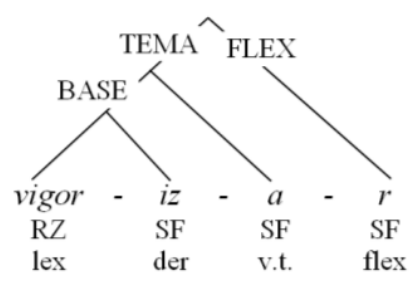

Recordamos que la clasificación de palabras en simples, complejas o derivadas se establece 
a partir del tema. El tema (Pena Seijas 1991: 72, 1999: 4314-4318) es el constituyente que queda cuando se suprimen los morfemas flexivos en una palabra (o, lo que es equivalente, el segmento al que se le añaden los morfemas flexivos). El tema complejo o derivado está formado por la raíz y afijos derivativos. De acuerdo con estas definiciones, en engordar y en vigorizar el tema está formado por la raíz léxica (gord-, vigor-), un morfema derivativo (prefijal en-, sufijal -iz-) y la vocal temática que, en los verbos, señala los límites del tema antes de la adición de los flexivos. La única diferencia apreciable entre (7) y (6a) radica en la colocación del afijo derivativo (anterior o posterior a la raíz). Ahora bien, la ordenación secuencial de esos elementos no parece una característica suficientemente relevante como para anular las evidentes semejanzas que se producen en ambos casos. Incluso, estos prefijos verbalizadores seleccionan la vocal temática del verbo derivado: en- y $a$ - son solidarios con la vocal temática de la primera conjugación al igual que -iz- (-iz-a-r) y al contrario que -ec- $(-e c-e-r)$.

Debemos concluir, por tanto, que verbos como embarcar, ensuciar, aclarar, descabezar y todos los que figuran en la columna 1 no pertenecen propiamente a la categoría de las formaciones parasintéticas. Se trata de verbos formados por derivación, en concreto por prefijación (Corbin 1980: 188-190), cuyo correlato más directo son los verbos derivados por sufijación, como se muestra en (7)-(6a). En embarcar nos hallamos ante una muestra de derivación prefijal heterogénea; en desembarcar habrá derivación prefijal homogénea.

Obsérvese, por otra parte, que este análisis hace innecesario plantearse la cuestión de si los morfemas flexivos o la vocal temática tienen propiedades derivativas, opción implícita en el análisis tradicional desde Darmesteter y mantenida posteriormente en multitud de trabajos de diferente orientación (vid. para la controversia González García 1997: 22-26, Stehlík 2013: 156157 y, especialmente, Serrano-Dolader 1995: 55-60, 2016: 16-18 y 2017: 56). Esta propuesta tenía, entre otros, el inconveniente de asignar valores distintos a la vocal temática o a los morfemas flexivos (una doble función) de acuerdo con la base de la palabra: si en andar o en palidecer nos hallaríamos ante morfemas inherentes a la categoría verbal, mera vocal temática (en el primer caso, por tratarse de un verbo primitivo; en el segundo, por el carácter transcategorizador del sufijo -ec-), en enfermar o embarcar, por el contrario, estos elementos serían también morfemas derivativos transcategorizadores, lo que, además de parecer una justificación creada ad hoc para estos casos, complica innecesariamente el análisis ${ }^{8}$.

Nuestro análisis evita también recurrir a un morfo cero derivativo (engord- $\varnothing$ - $a-r$, embarc- $\varnothing$ $a-r$ ), concepto que nos parece extremadamente arriesgado (Bosque 1983: 135, Pena Seijas 1991: 107-108), a pesar de ser utilizado con profusión en el análisis de la parasíntesis (Vid. SerranoDolader 2016: 16-18, 2017: 57).

\subsection{Parasíntesis y morfo discontinuo}

Al lado de los verbos examinados en el apartado anterior, los verbos que siguen el modelo envejecer (columna 2 del cuadro 1) suelen citarse como modelos prototípicos de formaciones parasintéticas. En estas formaciones es patente la existencia de un prefijo y un sufijo derivativos, cuya adjunción al radical es simultánea (8b-9b):

(8a) rojo $>$ *rojecer, *enrojo

(8b) rojo > en-roj-ec-e-r

(9a) cólera > *colerizar, *encólera 
La existencia de morfemas derivativos explícitos hace innecesario, en estos casos, recurrir a la existencia de morfos cero derivativos o acudir al carácter derivativo de los morfemas flexivos o de la vocal temática, aunque alguna de estas propuestas también se ha formulado (Vid. SerranoDolader 2016: 31, 2017: 71).

Sí es habitual, cuando se analizan estos verbos, mencionar la vinculación con el concepto de morfema (o morfo) discontinuo y, en concreto, con el más específico de circunfijo:

La circunfijación, conocida tradicionalmente como 'parasíntesis', es objeto de un amplio debate en la teoría morfológica actual (Pena Seijas 1999: 4326, n. 13).

Este [la parasíntesis] es el segundo de los procedimientos de formación de verbos derivados. Consiste en la adición de AFIJOS DISCONTINUOS, en concreto un prefijo y un sufijo elegidos simultáneamente (NGLE: 577-578).

Junto al reconocimiento del papel transcategorizador del prefijo o del sufijo independientemente considerados [...], queda una tercera vía de análisis de los verbos parasintéticos: la identificación de un afijo discontinuo que englobe inseparablemente a prefijo y sufijo (Serrano-Dolader 2017: 60).

A circumfix consists of two parts -a prefix and a suffix that together create a new lexeme from a base [...]. This kind of affixation is a form of parasynthesis, a phenomenon in which a particular morphological category is signaled by the simultaneous presence of two morphemes (Lieber 2010: 78).

Obsérvese que de las anteriores citas se deriva que la relación entre morfo discontinuo o circunfijo, de una parte, y parasíntesis, de otra, no es vista por todos los autores de una manera uniforme. Si para la RAE parasíntesis y adición de afijos discontinuos son términos sinónimos, para Serrano-Dolader son conceptos incompatibles. Esta segunda opción es la más adecuada, a nuestro modo de ver.

El hecho de que algunos autores analicen formas como enrojecer o encolerizar como verbos parasintéticos y otros como verbos formados por afijación discontinua o circunfijación (Martinet 1979, Bosque 1983: 133, Eguren 1991, González Vergara 1999) no implica que parasíntesis y circunfijación sean procedimientos semejantes. Al contrario, son explicaciones divergentes de un mismo fenómeno lingüístico. En esto coincidimos con Booij (2007) o Serrano-Dolader (2017):

Note that this kind of word-formation [=parasynthetic word-formation, LG] is different from circumfixation. In the latter case we have to do with one, discontinuous affix, whereas in the examples in (6) [se refiere a los parasintéticos italianos im-brutt-i-re, di-rozz-a-re, in-vecchi-a-re, LG] two independently occuring affixes are used simultaneously (Booij 2007: 56).

El prefijo y el sufijo de los parasintéticos parecen ser morfológicamente independientes y ejercen funciones distintas, de donde se deduce que su catalogación conjunta como un único circunfijo es contraria al funcionamiento de ambos afijos. Con ello, obvio es decirlo, no estamos negando que la circunfijación (entendida no como sinónimo de parasíntesis sino como un solo afijo discontinuo) pueda existir en las lenguas sino que simplemente queremos subrayar que no es el proceso lexicogenético que subyace a los parasintéticos (Serrano-Dolader 2017: 62).

Por ello, será necesario determinar las características de la parasíntesis y del morfo discontinuo para poder valorar cuál de estos análisis se ajusta de una manera más adecuada a las especiales características de este tipo de formaciones:

El 'circunfijo' es un afijo discontinuo que rodea la base. Está formado por la combinación de un prefijo y un sufijo mutuamente dependientes: ambos elementos se exigen mutuamente en la constitución del significante de la palabra en cuestión. En español puede interpretarse como 'circunfijo' el utilizado en la formación de las llamadas 'palabras parasintéticas', tipo sombra $\rightarrow$ en-sombr-ec-er; roj-o, - $a \rightarrow$ en-roj-ec-er (Pena Seijas 1999: 4326). 
Los morfemas discontinuos no son exclusivamente sintácticos [...], sino también morfológicos (en- - -ar, a- - ecer, etc.). En estos casos, prefijo y sufijo no constituyen morfemas diferentes, sino un solo morfema, ya que es uno solo el significado que entre ambos aportan (Bosque 1983: 133, cursiva en el original).

Hasta ahora, podía resultar relevante dilucidar si en engordar, en aclarar o en descabezar se trasluce una estructura tripartita - que salvaguarda su catalogación parasintética - o una estructura bimembre (con un único afijo discontinuo, o con una verbalización previa a la prefijación, o con una prefijación previa a la verbalización)—que sería razón suficiente para negar el carácter parasintético del verbo- (Serrano-Dolader 2017: 70-71).

Circumfixes are discontinuous morphemes consisting of two parts. One part of the affix occurs before the base while the other part occurs after the base. The two parts of the affix, however, constitute a single unit and express a single meaning (Kari 2015:11).

Las diferencias entre ambos procedimientos son palpables: en el caso de los morfemas (en realidad, morfos) discontinuos nos hallamos ante un único afijo, un único morfema, con un significado único ${ }^{9}$, por lo que se originan análisis bimembres (10). En el caso de la parasíntesis hay dos morfemas, dos afijos (un prefijo y un sufijo) independientes (debemos deducir que cada uno con su significado), cuya adjunción a una base es simultánea y no sucesiva (11):

(10) Circunfijación

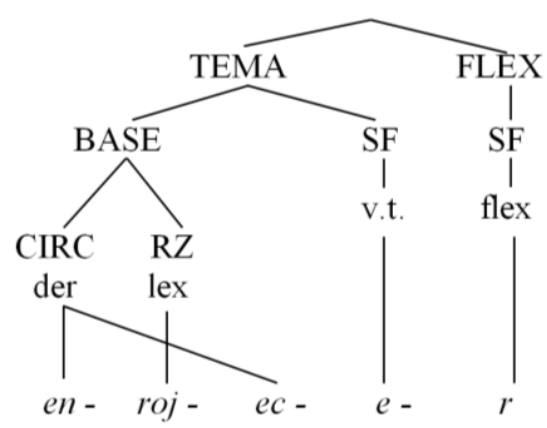

(11) Parasíntesis

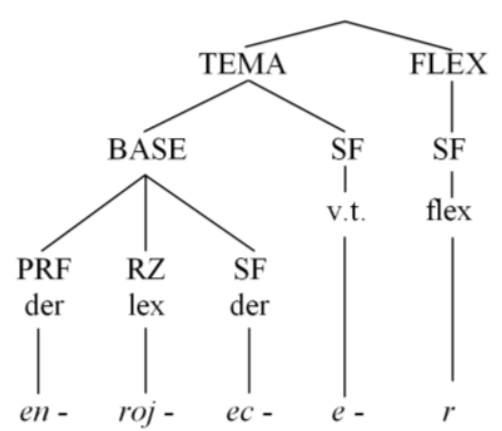

Las representaciones (10) y (11) dan cuenta adecuadamente del hecho de que en el segundo caso nos hallamos ante dos afijos de adjunción simultánea (segmentación en tres ramas), al contrario que en (10) donde la segmentación mantiene el principio de ramificación binaria.

En favor de (10) podemos ofrecer los siguientes argumentos:

El análisis parasintético implica que operan dos reglas de formación de palabras (prefijación y sufijación), intervienen dos morfemas cada uno con su significado. La circunfijación, por el contrario, implica que actúa un único morfema, una única regla de formación de palabras (RFP). De acuerdo con ella, enrojecer o encolerizar serán derivados directos de rojo o cólera, de la misma manera que palidecer lo es de pálido o vigorizar de vigor.

En segundo lugar, según el análisis parasintético entrarán en juego dos significados. La circunfijación, en cambio, comporta que solo hay un significado implicado, pues solo hay un morfema actuando ${ }^{10}$. Esto es lo que sucede si tenemos en cuenta el siguiente listado (las definiciones no son lexicográficas, pero se corresponden con las que figuran en el $D L E$ ):

(12) rojo > enrojecer 'ponerse rojo'

(13) pálido >palidecer 'ponerse pálido' 
(14) gordo > engordar 'ponerse gordo', 'hacer que alguien o algo se ponga gordo' (15) enfermo > enfermar 'ponerse enfermo', 'hacer que alguien o algo se ponga enfermo'

(16) cólera > encolerizar 'hacer que alguien se ponga colérico'

(17) vigor > vigorizar 'dar vigor'

La anterior relación nos muestra que podemos establecer una RFP para la formación de verbos que indican 'cambio' o 'causación' (dependiendo del verbo) a partir de nombres (sustantivos, adjetivos, adverbios):

\section{(18) $\mathrm{N}>\left[(\mathrm{AF})_{-}(\mathrm{AF})\right]_{\mathrm{v}}$ 'incoativo/causativo'}

La materialización mórfica de ese morfema derivativo ofrecería en castellano una variación en la que se asocian prefijos derivativos ( $a$-, en-), sufijos derivativos (-ec-, -iz-), todos opcionales, combinables de manera aleatoria (lo que origina nueve posibilidades). Algunas de dichas combinaciones originan prefijación, otras sufijación, otras derivación inmediata sin afijo o conversión, otras, en fin, circunfijación (las nueve combinaciones posibles no tienen idéntica productividad):

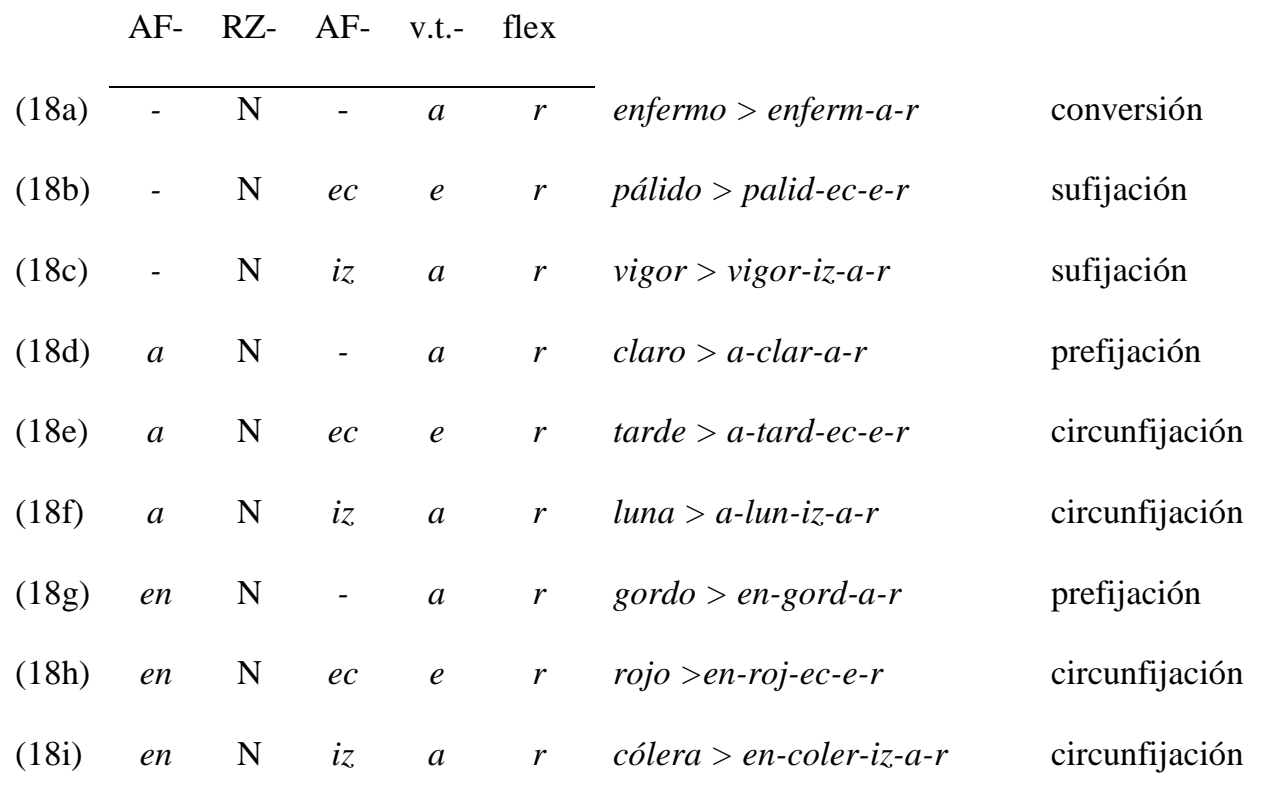

La prueba de que estamos ante una misma RFP nos la confirman las numerosas alternancias que permite la norma del español (agrandar [18d] / engrandecer [18h]) y arbitrariedades (duro > endurecer [18h], blando > ablandar [18d], ablandecer [18e] o emblandecer [18h]; mejor $>$ mejorar [18a], peor > empeorar [18g]). La norma del español selecciona entre las distintas posibilidades que ofrece el sistema, como hace en otros muchos casos (Coseriu 1973, Díaz Hormigo 2004). Se produce, por tanto, lo que Zacarías Ponce de León (2016) denomina "Rivalidad entre esquemas de formación de palabras"11. 
La cuestión del significado es sumamente importante porque el anterior análisis muestra que en envejecer no se puede asignar un sema particular a cada uno de los afijos en-_-ec-12. En suma (18) cumple los requisitos que Pena Seijas (2003) considera necesarios para que se pueda considerar que actúa una sola (no dos o varias) RFP:

\begin{abstract}
Hay, sin embargo, una manera de resolver en parte esta asimetría morfológica, este entrecruzamiento o superposición entre procedimientos de formación y significados. Y de esta manera trabajamos, de hecho, los que nos dedicamos al estudio de la morfología cuando queremos describir la morfología derivativa de una lengua particular. Es la siguiente: en aquellos casos en que a un mismo significado corresponden varios procesos o procedimientos morfológicos (concurrencia de afijos, afijación / composición, sufijación / prefijación, afijación / conversión, etc.), asociar a una sola regla de formación de palabras (RFP) aquellos procedimientos de formación que reúnan los dos requisitos siguientes: (a) que expresen un mismo significado, (b) que plasmen una relación categorial única entre la clase de la palabra base de derivación y la clase de la palabra derivada, com[o] sustantivos deadjetivales, adjetivos denominales, etc. (Pena Seijas 2003: 509).
\end{abstract}

Todos estos datos muestran, en nuestra opinión, que el análisis como morfemas discontinuos da cuenta de una manera económica y sencilla de los verbos examinados en este grupo. El carácter unitario del significado de estos morfos discontinuos queda aún más patente si se compara con aquellos casos en los que sí se produce realmente prefijación y sufijación simultánea y no sucesiva de dos morfemas distintos, según el modelo inalámbrico, desalmado o supersónico, que trataremos en el siguiente apartado ${ }^{13}$.

\title{
4.3 Parasíntesis por prefijación y sufijación simultáneas
}

Estos adjetivos se corresponden con las columnas 3, 4 y 5 del cuadro 1. Muchas de estas construcciones adoptan la forma del participio de un verbo inexistente por lo que suelen considerarse adjetivos parasintéticos: afamado, arrubiado, ensotanado, desalmado, desvergonzado, indoctrinado. Otros proceden de diferente origen, como es el caso de inalámbrico, supersónico (o impepinable, imperdible, regordete, etc., que no figuran en el cuadro).

La no existencia de una base verbal (*desvergonzar, *vergonzar) o sufijada (*vergonzado) justifica un análisis con tres ramificaciones para las primeras de estas voces. Lo mismo sucede con el segundo grupo, pues no se documentan separadamente una base prefijada (*inalambre) ni sufijada $\left({ }^{*}\right.$ alámbrico):

(19) Tema parasintético

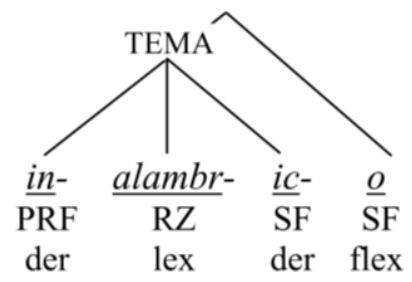

Una característica importante que permite contrastar estas formaciones parasintéticas con las estudiadas en el apartado anterior (morfo discontinuo) radica en que ahora sí nos hallamos ante la actuación de dos morfemas derivativos diferentes, cada uno con un significado y función 
diferenciada: in-, des-, super-, por una parte, -ic $(o, a)$, -ad(o, a),-ble, por otra, son afijos bien identificados en español, con unas características precisas, como se apreciará en (20)-(21).

La naturaleza parasintética de los adjetivos que figuran en esas tres columnas ha sido defendida desde la formulación tradicional de Darmesteter. Más recientemente, Serrano-Dolader (1995, 1999 y 2012a) también sostiene la naturaleza parasintética de estos adjetivos, que clasifica en tres grupos: a) el modelo desalmado se integra entre los adjetivos participales (1995: 156-164 y 1999 : 4731-4734); b) inalámbrico se incluye entre los adjetivos con referencias privativas-negativas o referencias numerales (1995: 177-184 y 1999: 4741-4744); por su parte, c) supersónico, junto con submarino, forma parte de los adjetivos locativos (1995: 165-168, 1999: 4734-4736 y 2012a) ${ }^{14}$.

Dado que en este subapartado nos hallamos ante adjetivos formados de manera muy diferente, convendrá que analicemos cada grupo independientemente.

\subsubsection{Modelos submarino, supersónico}

Desde Darmesteter este tipo de adjetivos ha sido incluido entre los parasintéticos por la disociación que se produce entre el significado y la forma. Si formalmente submarino es un derivado de un adjetivo preexistente (marino $>$ sub+marino), desde el punto de vista del significado ('relativo (-in[o]) a lo que está debajo (sub-) del mar') el análisis sería el inverso [[sub + mar] in(o) $]^{15}$. La lista de estos adjetivos es larga: antediluviano, extrauterino, intramuscular, precolombino, prerrafaelista, supersónico, superciliar, transiberiano, ultramontano, etc. Hoy en día el análisis mayoritario justifica esta discrepancia mediante las denominadas paradojas de encorchetamiento (Varela Ortega 1990: 55-57). En todo caso, este fenómeno parece diferente de la parasíntesis y nos lleva por otros derroteros.

Los procedimientos de formación de palabras operan sobre palabras (ocasionalmente sobre otras unidades más complejas) que actúan como base. Según el CORDE, la documentación más antigua del adjetivo marino, - $a$ es de mediados del siglo XIII, la de submarino, - $a$ de mediados del XVIII. En nuestra opinión queda claro que submarino se formó por prefijación sobre la base marino. Tratándose de adjetivos relacionales, la paráfrasis definitoria será en ambos casos 'relativo a'.

En nuestra opinión, es difícil defender, como principio general, que la constitución morfológica de una palabra compuesta o compleja se proyecte de manera directa, con una correspondencia biunívoca, en la interpretación semántica ("principio de composicionalidad", véase la discusión en Pena Seijas 2003: 506-508). Con todo, este es un debate que afecta al principio mismo del análisis morfológico y que, por tanto, sobrepasa el objetivo de nuestro estudio:

En la actualidad existen interpretaciones bastante divergentes respecto de la naturaleza de la relación derivativa. La cuestión se centra en torno a las posibles discordancias entre la estructura morfológica de una palabra y su interpretación semántica. Y el problema que se plantea es saber si tales discordancias permiten o no estudiar conjuntamente las relaciones morfológicas y las relaciones semánticas. A este respecto se mantienen dos posturas antagónicas: la de quienes defienden la asociación entre la estructura formal y la estructura semántica, y la de quienes sostienen la disociación entre ambas estructuras. Las dos posturas son conocidas como la tesis asociativa y disociativa, respectivamente (Pena Seijas 2003: 505-506).

El problema radica, a nuestro parecer, como en otros muchos casos, en la excesiva tendencia a unificar las reglas gramaticales, a veces prescindiendo de los datos lingüísticos. Y estos, los datos, muestran que hay procesos morfológicos en los que se aplica el principio de composicionalidad 
(medir > medición 'acción y efecto de medir') y otros en los que tal correspondencia no se produce (el caso más estudiado es precisamente el de las paradojas de encorchetamiento y los adjetivos aquí analizados).

Señala Serrano-Dolader (1995: 109-110), a propósito de paráfrasis como "mettre (la semence) en un champ" y la formación parasintética ensemencer: "Para nosotros, tal relación existe, pero sólo en el plano de la explicación semántica del derivado verbal, no como fundamento del proceso lexicogenético" (Serrano-Dolader 1995: 110).

Coincidimos en que la explicación semántica (la paráfrasis lexicográfica) y la constitución morfológica no tienen por qué corresponderse biunívocamente, lo cual no impide que pueda suceder (y suceda en muchas ocasiones).

En nuestra opinión, la interpretación semántica de tales palabras obedece más bien a las necesidades designativas del momento. Antimadridista puede aplicarse a los enemigos acérrimos de un club (coloquialmente conocido como el Madrid), a personas que estén en contra de los aficionados de ese club (madridistas) o a ambas entidades. Hay una indistinción que hacemos equivalente a la que se produce en algunas construcciones sintácticas y que no implica la existencia de tres procesos lexicogenéticos diferentes [[anti-madrid] ista], [anti[madrid-ista]], [anti-madridista] 16 .

El fenómeno que Serrano-Dolader (1995: 165-168, 2012a) denomina principio de coherencia paradigmática apoya nuestra consideración: estos derivados no se forman sobre el sustantivo semánticamente nuclear sino sobre el adjetivo que históricamente constituye su base (*interdedal $<$ dedo / interdigital < digital, *suprarriñonal < riñón / suprarrenal < renal).

Evidentemente, esta relativa independencia entre análisis morfológico e interpretación semántica no niega el carácter biplano del morfema (asociación de significado y significante, expresión y contenido) sino su proyección en la palabra compleja. Con todo, estas cuestiones superan con mucho, de nuevo, el objeto de nuestro estudio y, en definitiva, atañen solo indirectamente a este trabajo: el hecho de que submarino o intramuscular se analicen como palabras prefijadas (intra + muscul-ar, sub + mar-in-o) o como parasintéticas (intra + muscul + ar, $s u b+$ mar + in-o) afecta no tanto a la definición de la parasíntesis por prefijación y sufijación simultánea cuanto al análisis concreto de estas formaciones. Y, en este sentido, cada voz es única, cada vocablo tiene su historial. Así, en tanto que submarino históricamente se ha formado por derivación de marino, de la misma forma que antimadridista es un derivado prefijal de madridista, hechos corroborados en los corpus ${ }^{17}$, en otros casos el proceso sí puede ser parasintético: es el caso de prerrafaelista o supersónico. Como voz documentada, prerrafaelista precede en el tiempo a un inexistente pero posible ${ }^{*}$ rafaelista ${ }^{18}$. Lo mismo sucede con supersónico, que nos ilustra este proceso de formación de parasintéticos en una época fácilmente documentable: los avances técnicos que permitieron superar la velocidad del sonido reclamaron una voz que fuera adjetiva (ico) y elativa (super-): avión supersónico. Hasta ese momento, todos los aviones eran necesariamente subsónicos, por lo que este término latente quedó bloqueado, así como el adjetivo relacional sónico ${ }^{19}$. Sobre esta cuestión, relacionada con la constricción de no redundancia (Ackerman \& Goldberg 1996), volveremos en el apartado siguiente ${ }^{20}$. 


\subsubsection{Modelos inalámbrico, desalmado}

Por todo lo anteriormente expuesto, partiremos del hecho de que submarino o intramuscular son voces derivadas (doblemente derivadas, pues su base es también derivada: marino, muscular), lo que las diferencia de las escasas voces que incluimos en ese apartado en la categoría de parasintéticos por prefijación y sufijación simultáneas (tipo prerrafaelista o supersónico).

Los adjetivos que agrupamos en esta segunda categoría se corresponden con los adjetivos participales y con referencia privativa-negativa o numeral de Serrano-Dolader (1995: 177-184 y 1999: 4741-4744). Utilizaremos de modelo, respectivamente, desalmado e inalámbrico, para las cuales no existe base de derivación intermedia (19) y, de nuevo, desecharemos de este apartado aquellas numerosas creaciones, contenidas en las columnas 4 y 5 , que por distinto motivo no pueden ser incluidas entre las parasintéticas: cultismos de origen claramente latino o griego (amorfo, indemne, monocorde...), adjetivos carentes de sufijación derivativa (apétalo, bimano, heptasílabo, bicolor, incoloro, indefenso, etc.) o que presenten una base verbal (despedazado, desmigado, encuadernado, abrochado).

Eliminadas estas formas, el principal problema que plantean, a nuestro modo de ver, los escasos adjetivos parasintéticos restantes radica en el hecho de que de acuerdo con las reglas de formación de palabras estas construcciones podrían haber sido formadas de manera regular (principio de ramificación binaria o hipótesis de un afijo, una regla), tal como las formaciones que hemos desechado anteriormente del grupo de los parasintéticos (modelo submarino):

(20) -ic $(o, a)$ es un sufijo transcategorizador que forma adjetivos a partir de sustantivos (magia > mágico): alcohól-ico, cárn-ico, metód-ico...

(21) in- es un prefijo con valor negativo que se añade a adjetivos para formar adjetivos (útil > in-útil): in-exacto, in-aceptable, in-activo...

Consecuentemente inalámbrico se podría haber formado de manera regular en castellano aplicando de manera concatenada las reglas (20) y (21): alambre $e_{\mathrm{N}}>$ alámbr-icoADJ $>$ inalambricoADJ, (22):

(22) Tema derivado

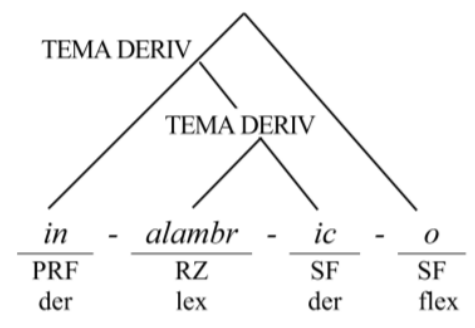

El anterior análisis debe hacer frente, sin embargo, a una importante objeción: la base intermedia ( ${ }^{\times}$alámbrico, $\left.-a\right)^{21}$ no existe en castellano (no está incluida en el $D L E$ ni en ninguno de los repertorios recopilados en el NTLLE) o, si queremos ser más precisos, ha sido formada con posterioridad a su hipotético derivado (derivación regresiva), como de hecho ha sucedido ${ }^{22}$. Ello nos lleva a la cuestión de las palabras posibles pero no existentes en una lengua y a la funcionalidad 
que les asignemos (Aronoff 1976: 17-19, Martínez-Arbelaiz 2001: 186-188, Iacobini 2010: 3, Serrano-Dolader 2015: 526-527).

Los datos que nos ofrecen los corpus académicos $(C O R D E)$ son claros:

Tabla 1. Documentación más antigua y frecuencia absoluta

\begin{tabular}{|l|l|l|}
\cline { 2 - 3 } \multicolumn{1}{l|}{} & $1^{\text {a }}$ Documentación & Frecuencia absoluta \\
\hline Desalmado & $1485-1496$ & 731 \\
\hline Desalmar & 1589 & 13 \\
\hline Inalámbrico & 1914 & 23 \\
\hline Alámbrico & 1929 & 9 \\
\hline Supersónico & 1951 & 11 \\
\hline Sónico & & 0 \\
\hline
\end{tabular}

Lo que se produce en estos casos es una discrepancia entre el sistema de RFP del español y la aplicación de esas reglas. En lugar de aplicarse sucesivamente, de acuerdo con el principio general de ramificación binaria, se aplican dos reglas en un mismo momento (en un mismo proceso dos procedimientos distintos, dice Serrano-Dolader 2017, en lo que concordamos ${ }^{23}$ ). La misma observación (remitimos a los corpus académicos) se puede hacer de otros adjetivos parasintéticos como incansable, imperdible, independiente, indesmayable, polifacético, etc. Lo que se produce, por tanto, es una anomalía en el orden de aplicación de las reglas de afijación, lo que provoca ramificaciones ternarias.

No podemos entrar en la mente del primer hablante del español que creó la palabra inalámbrico, pero sí podemos dar una explicación plausible del proceso de acuerdo con los conocimientos de la morfología actual. El recurso a las palabras posibles y no existentes, que actúan latentes en una lengua, se puede justificar a partir de un modelo analógico y paradigmático: las reglas de formación de palabras permiten crear series derivativas (paradigmas) según su sucesiva aplicación:

\begin{tabular}{|c|c|c|c|c|c|c|}
\hline & 1 & & 2 & & 3 & 4 \\
\hline (23) & gobierno & $>$ & gobernar & $>$ & gobernador & \\
\hline (24) & edificar & $>$ & $\begin{array}{l}\text { edificación } \\
\text { edificable }\end{array}$ & $>$ & edificabilidad & \\
\hline (25) & órgano & $>$ & orgánico & $>$ & inorgánico & \\
\hline (26) & amparo & $>$ & $\begin{array}{l}\text { amparar } \\
\text { desamparo }\end{array}$ & $>$ & desamparar & $>$ desamparado \\
\hline
\end{tabular}


Estas series, como ha señalado la morfología de base psicolingüística y cognitiva (modelos analógicos y conexionistas, Martín Vegas 2005), actúan realmente como esquemas sobre los que podemos formar palabras, las palabras realmente necesarias, aquellas que necesitamos para designar algo nuevo. Pensemos en los orígenes de la telegrafía sin hilos. Hasta ese momento las señales eléctricas viajaban necesariamente por cable. No era necesario, por tanto, crear el adjetivo alámbrico (y de hecho no se creó) porque no resultaba designativamente necesario (telegrafía alámbrica sería totalmente redundante). Ahora bien, cuando surgió la nueva tecnología (lo mismo sucedió en los años ochenta con los teléfonos inalámbricos, que revitalizaron el antiguo vocablo) fue necesario crear un adjetivo en el que se integrara ese rasgo negativo: se aplicó así la regla (25) en el tercer estadio, antes de que el segundo fuera precisado. Con posterioridad, la existencia del adjetivo inalámbrico permitió actualizar por contraposición el término alámbrico, que ahora sí se puede sentir necesario designativamente para aludir a la antigua tecnología. Las distintas corrientes enmarcadas dentro de la gramática funcionalista parten del hecho de que la necesidad comunicativa (la función) determina las características de las lenguas (los órganos). Creemos que esta es una manifestación clara de este principio de prevalencia de la necesidad comunicativa en el ámbito morfológico.

Hechos de esta naturaleza no son generales en la lengua, pero tampoco son extraordinarios y sus implicaciones superan los límites de este trabajo. En González García (2019b) mostramos otros casos en los que el derivado se documenta con anterioridad a la base ${ }^{24}$ : Los parasintéticos que aquí consideramos entran en esta categoría donde se produce una disociación entre el sistema de una lengua y su norma, o si preferimos entre el sistema y el habla: desde el punto de vista del sistema (RFP) legislador es un derivado de legislar (porque la regla (23) actúa en esta dirección). Sin embargo, los hechos demuestran que cronológicamente legislador es anterior a su base. La interpretación de esa voz, con todo, no plantea problema para el hablante porque la regla (23) sitúa cada palabra en su lugar paradigmático: "Así, en un determinado momento del español existen las parejas comprar comprador, vender vendedor, etc., pero no legislar al lado de legislador: la creación de legislar presupone por parte del creador un análisis previo de legislador como palabra afijada con -dor y viene a llenar el vacío en esa serie de derivación" (Pena Seijas 1991: 113).

Lo que se produce es una discrepancia entre el proceso secuencial según el sistema (22) y su aplicación histórica, en la que los procesos de prefijación y derivación se aplican simultáneamente y no en períodos distintos (19), originando análisis ternarios o parasintéticos.

\section{PARASÍNTESIS POR COMPOSICIÓN}

En las columnas 6-9 del cuadro 2 agrupamos estas formaciones compuestas, que tampoco son excesivamente numerosas. El modelo mileurista es el más productivo de la categoría en el español actual (más que el medieval misacantano). La escasez de formaciones hasta fechas tempanas (González García 2019b) explica que en las gramáticas se repitieran monótonamente las mismas voces: barriobajero, ropavejero, picapedrero, quinceañero, pordiosero, sietemesino, misacantano y pocos más (Serrano-Dolader 2012b: 428 y 2016: 24 repite corchotaponero, doceañista, venenosalival, misacantano, machihembrar, mancornar). 
Como en el caso anterior, el carácter parasintético de estas formaciones deriva del hecho de que los procesos de composición y derivación no se realizan de manera sucesiva siguiendo los modelos de RFP sino que ambos se aplican simultáneamente, pues las dos posibles bases, sean compuestas $\left({ }^{\times}\right.$mileuros, ${ }^{\times}$sietemeses, ${ }^{\times}$misacantar $)$o derivadas $\left({ }^{\times}\right.$eurista,${ }^{\times}$mesino, ${ }^{*}$ cantano $)$, no se atestiguan en la lengua (1-3). Los estudios más recientes han puesto de manifiesto la relación existente entre estas formaciones españolas y las que se documentan en otras lenguas románicas, germánicas y, especialmente, eslavas, con frecuencia denominadas, siguiendo a Bloomfield (1984 [1933]: 231), synthetic compounds (ingl. blue-eyed, al. rothaarig 'pelirrojo', Serrano-Dolader 2012b: 435-436, 2016: 23) o parasynthetic compounding (ruso strel + obraz $+n-y j$ 'flechiforme', Bisetto \& Melloni 2008).

A pesar de su escasa productividad, hemos observado que en los últimos años se detecta un cierto aumento en su creación (González García 2019b), con predominio de los sufijos derivativos -ismo, -ista sobre el tradicional $-\operatorname{er}(o, a)$ que, aun así, sigue actuando: mileurismo (DLE 2014), milloneurista, cortoplacista (DLE 2014) y largoplacista, cuentapropista (DLE 2001), madresolterismo, novorriquismo, buenrollismo, guerracivilismo, sincorbatismo, sincomplejismo, mediocampista (DLE 2014), cerocerismo, todocampista, vagacampista, terraplanista (o tierraplanista), sacapuntero 25 , malrollero, clasemediero (CVC), sincebollero, concebollero (distintos partidarios de la tortilla de patatas) ${ }^{26} \mathrm{y}$, con un sufijo distinto, diezminutal (mediciones diezminutales), cadaunada 27.

La proliferación de este tipo de creaciones no ha pasado inadvertida a la sagacidad de Javier Marías (El País Semanal, "Palabras que me impiden seguir leyendo” [16/12/2018]):

En cuanto al horroroso y mal formado "ojiplático", que ya ha pedido su ingreso en el Diccionario, qué quieren. Pretender que a partir de "se me quedaron los ojos como platos" se cree ese engendro, es como aspirar a que también se incluyan "carnigallináceo", "pelipúntico" y "peliescárpico" para designar cómo nos quedamos cuando nos emocionamos o nos llevamos un susto.

No todos los modelos de formación de este tipo son reconocidos como parasintéticos. Así, la $N G L E$ (749-750) señala que:

Aunque es habitual afirmar en la tradición que en la parasíntesis se dan simultáneamente la composición y la derivación, se piensa hoy que no se obtienen segmentaciones ternarias en esos derivados. Así pues, no se reconocen en estas palabras tres componentes paralelos y segmentables al mismo tiempo (misa-, cant-y -ano; por-, dios-y -ero; mil-, eur-e -ista, etc.), sino solo dos (misacant-ano, pordios-ero, mileur-ista) [...]. Esta forma de segmentación no reduce propiamente la parasíntesis a la pauta «composición + derivación», puesto que la derivación no se aplica a un compuesto existente.

Tampoco Serrano-Dolader (1995) incluye entre las formaciones parasintéticas por composición muchas de las arriba mencionadas, al igual que Varela Ortega (1990: 114-119), que engloba en una sola categoría de "casos de derivación externa o derivación de todo el compuesto" lo que para nosotros son dos: 'derivados de compuestos' (paracaidista, sacamolero) y verdaderos parasintéticos (misacantano, cuentadante).

Como hemos hecho en casos anteriores, abordaremos este tipo de parasintéticos de acuerdo con los diferentes modelos de formación de palabras que identificamos bajo esta etiqueta:

1) Modelo pordiosero

2) Modelo cortoplacista

3) Modelo mileurista 


\subsection{Modelo pordiosero}

Además de la que nos sirve de modelo (pordiosero), pertenecen a esta clase algunas formas como porcentaje, sinhilismo 28 , y otras de uso reciente y ocasional como sincebollero, concebollero, sincorbatismo, sincomplejismo, sinhogarismo, etc. Lo característico de estas construcciones es que interviene en su formación una preposición, no un prefijo (como las preposiciones son palabras, en ellas interviene la composición, no la prefijación). La base de derivación sobre la que actúa el afijo derivativo es, por tanto, una frase preposicional más o menos fijada: por dios, con cebolla, sin corbata, sin complejos... Dado que estas cadenas no están suficientemente fijadas para hablar de una palabra compuesta (al contrario de lo que sucede con sinfín, sinnúmero, sinsabor, sinsentido, sinsustancia, sinvergüenza, pormenor, porvenir, entreguerras) es lícito defender (si se parte del supuesto de que las bases de derivación han de ser palabras, no unidades sintácticas) que composición y derivación se producen en estos casos simultáneamente y no sucesivamente ${ }^{29}$. De esta manera podremos diferenciar -en ese apartado en el que entra en juego una frase preposicional- entre derivados prototípicos, cuya base es una palabra compuesta formada a partir de la fijación de una frase preposicional (27) y otro tipo de formaciones, entre ellas las parasintéticas (29), en las que se produce composición y derivación simultáneas:

(27) Palabras derivadas de compuestas por sufijación: pormenor > pormenorizar, sinvergüenza > sinvergüencería, ensimismar > ensimismamiento.

(28) Palabras formadas por derivación inmediata (es decir, sin intervención de un afijo derivativo) a partir de una frase preposicional: entre comillas > entrecomillar, en sí mismo > ensimismar.

(29) Palabras parasintéticas, formadas por sufijación a partir de una frase preposicional: por + dios $+\operatorname{er}(o)>$ pordiosero.

(27a) Derivada de compuesta

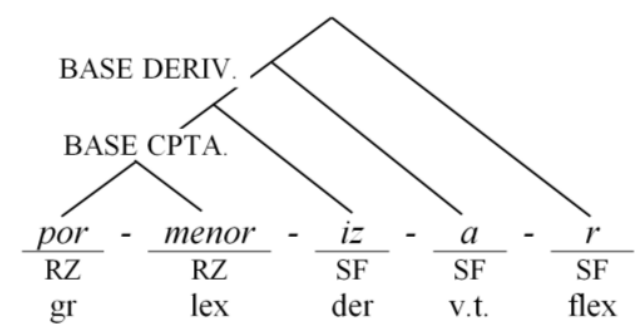

(29a) Parasintética

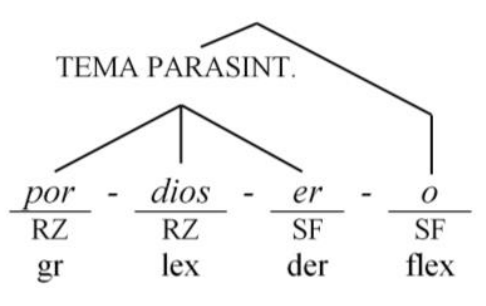

Como es sabido, la frontera entre un sintagma libre, un sintagma fijado y una palabra compuesta es gradual, no discreta, por lo que los límites entre (27) y (29) también lo serán: pormenor figura en el DLE como sustantivo masculino; por Dios aparece como expresión; entre comillas no figura a pesar de su indudable fijación en poner entre comillas; por ciento se considera locución adverbial; sin corbata es, evidentemente, un sintagma libre.

La diferencia, en este grupo, entre una palabra derivada de compuesta (pormenorizar, sinvergüencería) y una palabra parasintética (pordiosero, sincorbatismo) radicaría en el grado de fijación de la base preposicional. Los grados extremos prototípicos (centro) son fáciles de adscribir 
a una u otra categoría, los casos intermedios (periferia) no tanto. En nuestra opinión, es lícito hablar de parasíntesis cuando la base es un sintagma libre (sincorbatismo) o el grado de fijación de la base todavía no ha originado una palabra plenamente compuesta (compuesto morfológico o compuesto propio), como es el caso de pordiosero, porcentual o porcentaje. En caso contrario hablaremos de un derivado de un compuesto (pormenorizar, ensimismamiento).

Lo que acabamos de señalar es también válido, aun en mayor medida, para los parasintéticos que siguen los modelos cortoplacista y sietemesino.

\subsection{Modelos cortoplacista y mileurista}

El modelo mileurista ha sido analizado en varios lugares a lo largo de este trabajo por lo que no insistimos mucho en él (1-3). La principal diferencia con cortoplacista radica en que en el primer caso los dos primeros constituyentes del análisis ternario pertenecen a la categoría de las unidades sintácticas libres (mil euros es una frase sustantiva), en tanto que en cortoplacista esos componentes forman parte de una locución, a corto plazo (locución adverbial en DLE: s. v. plazo), lo que enlaza con la argumentación con la que finalizamos el apartado anterior. En ambos casos nos hallamos ante formaciones que se apartan del modelo prototípico de las palabras formadas a partir de otras palabras existentes (ramificación binaria): baloncestista (< baloncesto), paracaidista (<paracaídas).

Esta es la base en la que se fundamenta la Real Academia para negar que en este tipo de parasíntesis haya composición. Recordamos que para esta institución (NGLE: 749-750) en estos casos procede un análisis bimembre mileur-ista al tiempo que niega la existencia de composición porque (repetimos la cita): "Esta forma de segmentación no reduce propiamente la parasíntesis a la pauta "composición + derivación», puesto que la derivación no se aplica a un compuesto existente". Si entendemos bien a la Academia, debemos interpretar que lo peculiar de estas construcciones es que se trata de derivados (de ahí el análisis bimembre) de unidades sintácticas (sintagmas, no palabras compuestas). Como el límite entre sintagma libre, sintagma fijado y palabra compuesta es gradual, volvemos así a nuestras consideraciones anteriores, sobre lo problemático de fijar el límite de la palabra compuesta. Así, por ejemplo, González Ollé \& Casado Velarde (1992: 106) señalan: "no consideramos parasintéticos vocablos como aguabenditera, cuentacorrentista, estadounidense, noventayochismo, tercermundista, etc., ya que, si bien no existen *benditera, *correntista, *unidense, *(y)ochismo, *mundista, etc., sí se dan, en cambio, los compuestos agua bendita, cuenta corriente, Estados Unidos, (generación del) noventa y ocho ([18]98), tercer mundo."

Lo que hacen estos autores es, pues, diferenciar entre derivados de compuestos (los mencionados en la cita) y parasintéticos, distinción bien asentada. En lo único en que podríamos discrepar es en la consideración como palabra compuesta de alguno de los ejemplos aducidos (agua bendita, cuenta corriente, tercer mundo). Esas mismas unidades, por el contrario, son analizadas por Serrano-Dolader (1995: 216-217) "como derivados de lexías y no como parasintéticos en composición” (1995: 217-218). La distinción no es meramente terminológica, porque, más allá de los derivados de compuestos, Serrano-Dolader (1995) restringe sumamente el concepto de parasíntesis al contraponer las formaciones propiamente parasintéticas a 
a) falsos parasintéticos o pseudoparansitéticos,

b) los derivados de lexías y

c) los (difícilmente admisibles) generadores de lexías.

Los derivados de lexías no plantean problemas terminológicos, su base de derivación es un sintagma fijado (agua bendita > aguabenditera, cuenta corriente > cuentacorrentista, que González Ollé \& Casado Velarde 1992 analizan como derivados de compuestos) ${ }^{30}$. Los generadores de lexías son muy problemáticos y atentan contra la intuición del hablante:

Las lexías ropa vieja o vara larga son derivadas a partir de las formaciones ropavejero y varilarguero. Proponemos para formaciones del tipo ropavejero o varilarguero el nombre de generadores de lexías, puesto que su constitución como unidad con un determinado significado implica inmediata y obligatoriamente el surgimiento de la lexía correspondiente en la lengua (y, posiblemente, en el discurso) (Serrano-Dolader 1995: 219).

Para Serrano-Dolader, ropa vieja no es la base de derivación de ropavejero. Entre ellos solo hay una relación semántica de transparencia: "La existencia de tal relación de transparencia entre ropa

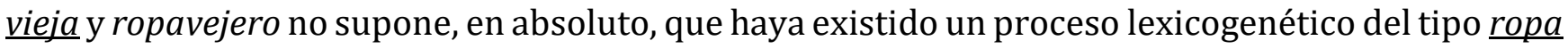
vieja (A-B) > ropavejero" (Serrano-Dolader 1995: 220).

Para ropavejero propone, por tanto, un análisis monolexemático (Serrano-Dolader 1995: 219): "un lexema inanalizable desde el punto de vista sincrónico-dinámico", a partir del cual se generaría la lexía ropa vieja. Lo artificioso de esta categoría salta a la vista cuando se compara con los pseudoparasintéticos (sietemesino, veinteañero, cadañal...), que analiza como derivados de sintagmas libres ([siete mes] ino). Desde nuestro punto de vista (y creemos que no es necesario argumentar en favor de ello) siete meses y ropa vieja son dos muestras de lo que denominaremos frases sustantivas (un tipo de sintagma libre) y, por tanto, el análisis de ropavejero y sietemesino debe ser semejante. Ambas son formaciones prototípicamente parasintéticas si atendemos a la definición del término (el proceso de derivación no se aplica sobre una palabra sino sobre una unidad sintáctica, por lo que en esa palabra se condensan simultáneamente los procedimientos de composición —unión de dos raíces-y sufijación derivativa).

Eliminados todos estos casos -a), b), c) -, para Serrano-Dolader (1995: 242-256) la verdadera parasíntesis queda reducida a aquellas palabras en las que el proceso de sufijación se aplica "sobre un compuesto que única y exclusivamente puede aparecer como tal forma compuesta en el seno del parasintético". Es una restricción muy fuerte que prácticamente elimina la parasíntesis por composición del inventario de procedimientos de formación de palabras en español (véase la lista señalada anteriormente: corchotaponero, doceañista, venenosalival, misacantano, machihembrar, mancornar). Traducido en nuestra terminología supone aceptar que en la parasíntesis la sufijación actúa sobre bases no posibles (*corchotapón) en tanto que los pseudoparasintéticos, los derivados de lexías y los generadores de lexías actúan sobre bases sintácticamente posibles pero no existentes como palabras (siete meses, agua bendita, ropa vieja) ${ }^{31}$.

Esto nos lleva de nuevo al status de la palabra compuesta en una lengua y a la dificultad para establecer un límite entre un compuesto posible pero no existente y un compuesto no posible. En el caso de la afijación, la diferencia entre palabra posible y no posible es fácil de determinar, porque las reglas son más precisas. Pero, en el caso de los compuestos, limitar los esquemas operativos es más complicado. En concreto, muchos de los compuestos del español se forman por fijación de sintagmas libres (metomentodo, hazmerreír, bienmesabe, quitaipón) por lo que es problemático señalar qué combinaciones no son productivas: si analizamos la escasa serie de parasintéticos que 
Serrano-Dolader ofrece, comprobamos que todavía se podría reducir al mínimo porque en algunos casos es posible identificar el modelo que actúa en la formación de la palabra compuesta no existente: en corchotaponero, ${ }^{\times}$corchotapón 'tapón de corcho' sigue el modelo de casapuerta 'puerta de casa', zarzamora 'mora de zarza', pavipollo 'pollo de pavo', según reconoce el propio SerranoDolader (1995:143). Machihembrar y mancornar (columna 9) se forman sobre bases compuestas de sustantivo + sustantivo, como capisayo, carricoche, casatienda ${ }^{32}$, etc.

Para entender qué quiere decir 'compuesto y derivado simultáneamente' debemos retomar el fundamento de la tradicional distinción entre palabras simples, compuestas y derivadas (olvidemos ahora las parasintéticas), fundamento que nos lleva a matizar (no negar) esa distinción básica trimembre de la morfología tradicional. En ella se entrecruzan y mezclan -como sucede en otros casos en la gramática tradicional- dos oposiciones básicas, que conviene diferenciar. En efecto, una palabra puede ser simple y derivada o derivada y compuesta, lo cual es contradictorio si esos tres miembros se consideran equipolentes. En realidad, la tradición gramatical (Seco 1975: 129-130) contrapone palabras primitivas a derivadas y simples a compuestas (cuadro 3), de manera que una palabra podrá ser simple y derivada pero no simple y compuesta.

Recordamos que el fundamento de esta clasificación radica en el concepto de tema. El tema puede ser (Pena Seijas 1991: 72 y 1999: 4314-4318):

i) Según el número de raíces: simple / compuesto

ii) Según le presencia de morfemas derivativos: primitivo / derivado (o complejo) ${ }^{33}$.

Cuadro 3. Clases de palabras según el tema. Elaboración propia.

\begin{tabular}{|l|l|l|}
\hline SIMPLE & PRIMITIVA & DERIVADA \\
\hline COMPUESTA & mano & manual \\
& manecilla \\
\hline & manamatar & manamafactura \\
\hline
\end{tabular}

De esta manera podremos establecer cuatro tipos principales de palabras de acuerdo con la tipología de temas:

1) Simple primitiva (mano)

2) Simple derivada (manual, manecilla)

3) Compuesta primitiva (pasamanos, maniatar)

4) Compuesta derivada

Esta última categoría es compleja porque los procesos de composición y derivación pueden aplicarse secuencialmente en distinto orden (primero composición y después derivación o viceversa): la base puede ser una palabra compuesta sobre la que se aplica la derivación o bien 
podemos hallarnos ante una palabra compuesta en cuyo interior una de las bases ha sido derivada con anterioridad. Distinguimos así entre:

4.1) Derivada de compuesta: Pasamanería ([[pasa-manos]+ería]).

4.2) Compuesta con derivación interna: Manufactura ([manu+[fact-ura]]), Aguardiente ([agua+[ardie-nte]]).

Lo peculiar de las palabras parasintéticas por composición radica en que no se pueden encuadrar en ninguna de esas cinco categorías. En estas, la clasificación tripartita criticada (simple, compuesta, derivada) es operativa si se atiende al último proceso que actúa. Así, podremos decir que mano es una palabra simple; manual es derivada; pasamanos y maniatar, compuestas, pasamanería, derivada, y manufactura o aguardiente, compuestas. En las palabras parasintéticas esta remisión no es posible, porque no hay un último proceso, sino dos simultáneos.

En contra de lo que afirma la Academia, estas palabras pueden ser consideradas compuestas porque contienen un tema compuesto (hay más de una raíz). El problema que se plantea es dilucidar cuándo se entiende que ese tema compuesto se corresponde con una palabra compuesta (es decir, con una palabra existente). En nuestra opinión ${ }^{\times}$sietemés no es una palabra existente por lo que defendemos el carácter prototípicamente parasintético de sietemesino. ${ }^{\times}$Sietemés podría existir, pues tenemos ochomil, pl. ochomiles ${ }^{34}$, sobre el cual se pueden formar ulteriores palabras, como el derivado ochomilista:

[...] en el cerebro de los 'ochomilistas' (montañeros que cubren esta altura en sus escaladas) se producen una serie de alteraciones neurológicas claramente visibles con resonancia magnética (CORPES, prensa, España, 2007).

Esta distinción entre ochomilista y mileurista creemos que debe ser mantenida y destacada, para dar cuenta en el plano histórico de los procesos reales de formación de palabras. De esta manera, la parasíntesis es un recurso que atenta doblemente contra la Word Based Hypothesis de Aronoff (1976: 21): "All regular word-formation processes are word-based. A new word is formed by applying a regular rule to a single already existing word. Both the new word and the existing one are members of major lexical categories."

Esta hipótesis sostiene que las RFP se aplican sobre palabras existentes, lo que ha llevado al conocido debate acerca del papel de las palabras posibles pero no existentes en la morfología léxica, ya comentado. Pero esta hipótesis implica también que la base de los procesos morfológicos son necesariamente palabras (unidades morfológicas) y no frases o sintagmas (entidades sintácticas), de donde se deriva el principio llamado No-Phrase Constraint: "Lexical rules do not apply to syntactic phrases to form morphologically complex words" (Botha 1984: 137)35. Las formaciones parasintéticas incumplen este principio, como hemos visto, porque operan con unidades sintácticas (frases preposicionales, frases sustantivas) o unidades a medio camino, todavía no fijadas como palabras compuestas (locuciones), como base.

De esta manera, la parasíntesis traslada ocasionalmente a algunos sufijos $(-\operatorname{er}(o, a),-i n(o, a)$, ista, -ismo, -al) la capacidad reservada a una clase determinada de prefijos externos (ex-, pro-, anti, contra-) de operar sobre bases sintagmáticas ([ex [primer ministro]], [pro [derechos humanos]) (Serrano-Dolader 2002, Felíu Arquiola \& Gil Laforga 2012), con la diferencia de que en el caso de la parasíntesis el resultado o educto es una palabra plena. Barriobajero es un adjetivo; en campaña 
pro barrios deprimidos, por el contrario, barrios deprimidos es una frase sustantiva antes y después de la adjunción de la partícula pro.

Lo que unifica, por tanto, los dos tipos de parasíntesis generalmente reconocidos es el actuar sobre palabras no existentes, no disponibles aún en el repertorio léxico de una lengua: sea un derivado aún no formado en el caso de la parasíntesis por prefijación y sufijación simultáneas (inalámbrico, supersónico, desalmado) o un compuesto en el caso de parasíntesis por composición y sufijación simultáneas (sietemesino, pordiosero, cortoplacista).

\section{LAS FORMACIONES PARASINTÉTICAS COMO MANIFESTACIÓN DE UNA LINGÜÍSTICA DEL HABLA}

El léxico de una lengua es impredecible, pues las necesidades designativas de los hablantes también lo son. La gramática de una lengua integra una serie de reglas que determinan los procedimientos por los que se pueden crear palabras nuevas. Estos procedimientos actúan de manera regular originando una gran cantidad de vocablos posibles (que, con el tiempo, pueden desmotivarse o reanalizarse), de los cuales no todos realmente son necesarios (se trata de las palabras posibles pero no existentes porque actúa algún tipo de bloqueo). Un componente importante de estas reglas es la información de entrada y salida, lo que ocasiona que las reglas se pueden aplicar cíclicamente:

(30) Nacerv $_{V}>$ nación $_{N}>$ nacional $_{A D J}>$ nacionalizarV $_{V}>$ nacionalizable $_{A D J}>$ desnacionalizable $_{A D J}>$ desnacionalizabilidad $_{\mathrm{N}} \ldots$

Estas series derivativas forman parte del conocimiento gramatical del hablante/oyente ideal (de la lengua saussureana, de la competencia chomskiana). Son creaciones realizadas de acuerdo con el sistema de la lengua, con la gramática de la lengua. Suelen ser respetadas por los hablantes cuando se siente la necesidad de crear una palabra. Pero también es posible quebrantarlas. También es posible una lingüística del habla (Saussure 1945 [1916]: cap. 4), o de la actuación, vinculada a las necesidades expresivas de cada acto comunicativo ${ }^{36}$. En este momento es cuando aparece la parasíntesis. La parasíntesis no anula las RFP, simplemente las puentea, necesita el resultado $C$ sin pasar previamente por $B(A>C)$, por más que este eslabón intermedio actúe de manera latente (semaforización se creó con anterioridad a semaforizar, pero implica su virtual existencia).

Es el caso de inalámbrico, desalmado, supersónico, sietemesino, quinceañero, mileurista y de las palabras que siguen su modelo. Ocupan un lugar discreto en la morfología del español (Saussure preconizaba la prioridad de la lingüística de la lengua sobre la del habla) pero creemos que su importancia no debe ser infravalorada y su carácter especial merece ser resaltado. En su lúcido trabajo, Serrano-Dolader (2017: 70) señala:

En nuestro planteamiento actual, interpretamos la parasíntesis como un proceso lexicogenético más que como un procedimiento lexicogenético. En concreto, es un proceso creativo que se sirve de procedimientos varios combinados. Lo peculiar de tal proceso, y lo que lo singulariza en relación con los otros procesos de aplicación de los procedimientos lexicogenéticos disponibles en las lenguas, es el hecho de que sea fruto de la aplicación conjunta y solidaria de dos (o más) procedimientos de creación léxica. Desde este punto de vista, y corrigiendo lo que hemos propuesto en otros lugares ( $c f r$. Serrano-Dolader 1995 y 1999), lo significativo no es defender el carácter tripartito (y no binario) del que considerábamos entonces procedimiento parasintético, sino asumir 
que lo caracterizador y singularizador de la parasíntesis es el hecho de que, como proceso léxico, combine solidariamente varios procedimientos lexicogenéticos.

Es curioso que llegando a conclusiones diametralmente opuestas en cuanto a la naturaleza y alcance de la parasíntesis, haya coincidencia de fondo entre lo que defendemos en estas páginas y las afirmaciones de Serrano-Dolader. Fijémonos, sobre todo, en las dos primeras líneas: la parasíntesis es un proceso no un procedimiento. Por eso comenzamos el resumen de este trabajo señalando que, en nuestra opinión, a pesar de que la parasíntesis no es un procedimiento de formación de palabras, sí existen palabras parasintéticas como resultado de diferentes procesos de formación de palabras. La parasíntesis surge cuando los hablantes utilizan (ponen en práctica: acto de habla) los procedimientos de formación de palabras que la lengua les ofrece (composición, derivación) de forma, digamos, torticera. La parasíntesis es una violación de reglas, como tal ocasional (caso de hacerse regular se convertiría en hecho de lengua ${ }^{37}$ ). Por tal motivo, no podemos considerar parasintéticas formaciones regulares y muy productivas propias del castellano como embarcar, aclarar, enrojecer...

\section{CONCLUSIONES}

En este estudio hemos procedido al análisis de los diferentes tipos de formaciones generalmente encuadrados bajo la etiqueta de parasíntesis.

De entre las formaciones parasintéticas hemos eliminado aquellas a las que es posible asignar un análisis más simple: la prefijación (embarcar) o la circunfijación (envejecer).

Las construcciones que propiamente se pueden considerar parasintéticas (por doble afijación simultánea: inalámbrico, desalmado; por composición y derivación simultáneas: sietemesino, pordiosero, cortoplacista) se caracterizan por actuar sobre bases no documentadas como unidades morfológicas (palabras posibles no existentes). Se produce, por tanto, una anomalía, pues, en el primer caso, la base de derivación no existe o se crea posteriormente ( ${ }^{\star}$ alámbrico, *inalambre), y, en el segundo, los afijos derivativos no actúan sobre palabras sino sobre construcciones sintácticas (por Dios, siete meses, a corto plazo).

Esta anomalía se justifica en el marco de una lingüística del habla. Por necesidades designativas, los hablantes incumplen el orden serial en la aplicación de las RFP que determina el sistema morfológico de una lengua. Esta discrepancia entre el sistema y su puesta en práctica (habla) es lo que podemos denominar propiamente parasíntesis.

\section{Financiación}

Este trabajo se ha realizado en el seno del Grupo de Investigación HISPANIA (G000208) de la Universidad de A Coruña, que ha sido reconocido como Grupo de Potencial Crecimiento y ha recibido una ayuda de consolidación de la Xunta de Galicia (ref: ED431B 2019/28). 


\section{Bibliografía}

Ackerman, F. \& Goldberg, A. E. (1996): “Constraints on adjectival Past Participles”, en A. E. Goldberg (ed.): Conceptual Structure, Discourse and Language. Stanford: CSLI, pp. 17-30.

Alcoba RuEdA, S. (1987): “Los parasintéticos: constituyentes y estructura léxica”, Revista Española de Lingüística 17/2, pp. 245-267.

Alemany Bolufer, J. (1920): Tratado de la formación de palabras en la lengua castellana. Madrid: Librería General de Victoriano Suárez.

Aronoff, M. (1976): Word Formation in Generative Grammar. Cambridge, Massachusetts and London: The MIT Press.

Bisetto, A. \& Melloni, C. (2008): “Parasynthetic Compounding”, Lingue \& Linguaggio 2, pp. 233-259.

Blanco Rodríguez, L. (1993): “Sobre la parasíntesis en español”, Verba 20, pp. 425-432.

BLOOMFIELD, L. (1984 [1933]): Language. New York: Henry Holt.

$B N E=$ BIBLIOTECA NACIONAL DE EsPaÑA: Hemeroteca digital. http://hemerotecadigital.bne.es/index.vm. [fecha de consulta: 15/02/2019]

BooIJ, G. (2007): The Grammar of Words: An introduction to linguistic morphology. Oxford: Oxford University Press.

Bosque, I. (1983): “La Morfología”, en F. ABAD \& A. GARCía BERRIo (coords.): Introducción a la lingüística. Madrid: Alhambra, pp. 115-153.

Bosque, I. \& Demonte, V. (dirs.) (1999): Gramática Descriptiva de la Lengua Española, vol. 3. Madrid: Espasa.

Botha, R. P. (1984): Morphological Mechanisms. Oxford: Pergamon Press.

Campos Souto, M. (2012): “Definición lexicográfica y morfología léxica en un diccionario histórico: el caso de los sustantivos terminados en -ería en el $D H$ ”, en G. Clavería, M. FreiXAS, M. Prat \& J. Torruella (eds.): Historia del léxico: perspectivas de investigación. Madrid-Frankfurt am Main: IberoamericanaVervuert, pp. 305-340. https://doi.org/10.31819/9783865278784-010.

CASAdo Velarde, M. (2015): La innovación léxica en el español actual. Madrid: Síntesis.

$C D H=$ INSTITUTO DE INVESTIGACIÓN RAFAEL LAPESA DE LA REAL ACADEMIA ESPAÑOLA (2013): Corpus del Nuevo diccionario histórico (CDH). http://web.frl.es/CNDHE. [fecha de consulta: 15/02/2019].

Corbin, D. (1980): “Contradictions et inadéquations de l'analyse parasynthétique en morphologie dérivationnelle", en A. M. DesSAuX-Berthouneau (ed.): Théories linguistiques et traditions gramaticales. Lille: Presses Universitaires de Lille, pp. 181-224.

CoRBIN, D. (1997): "Entre les mots possibles et les mots existants: les unités lexicales à faible probabilité d'actualisation", en D. Corbin, B. Fradin, B. Habert, F. Kerleroux \& M. Plénat (eds.): Silexicales 1. Mots possibles et mots existants. Forum de morphologie. Actes du colloque de Villeneuve d'Ascq. Villeneuve d'Ascq: Presses de l’Université de Lille III, pp. 79-89.

CORDE = REAL ACADEMIA ESPAÑola: Corpus diacrónico del español (CORDE). http://www.rae.es. [fecha de consulta: $12-15 / 02 / 2019]$.

Coseriu, E. (1973): “Sistema, norma y habla”, en Teoría del lenguaje y lingüística general, Madrid: Gredos, pp. 11-113.

CoSERIU, E. (1978): Sincronía, diacronía e historia. Madrid: Gredos. 
CVC = Centro Virtual Cervantes y ObServatori de Neologia de la Universitat Pompeu Fabra: Banco de neologismos. https://cvc.cervantes.es/lengua/banco neologismos/default.htm. [fecha de consulta: 15/02/2019].

DARMESTETER, A. (1895): Cours de grammaire historique de la langue française. Troisième partie: formation des mots et vie des mots. Paris: Librairie Ch. Delagrave.

DCECH = COROMINAS, J. y J. A. PASCUAL (1980-1991): Diccionario crítico etimológico castellano e hispánico. Madrid: Gredos.

DíAZ Hormigo, M. T. (2004): "Restricciones del sistema y restricciones de la norma en la formación de palabras", Lingüística en la red 2, pp. 1-26.

DLE = REAL ACADEMIA ESPAÑola (2014): Diccionario de la lengua española. Madrid: Espasa.

EGUREN, L. (1991): “Representaciones geométricas en la morfología del español: la parasíntesis", en C. MARTín VIDE (ed.): Lenguajes naturales y lenguajes formales. Actas del VI congreso de lenguajes naturales y lenguajes formales, Vol. VI.2. Tarragona: PPU, pp. 479-492.

FÁBregas, A., Felíu, E., MARTín, J. \& PAZó, J. (eds.) (2012): Los límites de la morfología. Estudios ofrecidos a Soledad Varela Ortega. Madrid: Servicio de Publicaciones de la Universidad Autónoma de Madrid. https://doi.org/10.15366/l.morfologia2012.

Felíu ARQuiola, E. (2003): Morfología derivativa y semántica léxica: la prefijación de auto-, co- e inter-. Madrid: Ediciones de la Universidad Autónoma.

Felíu ARquiola, E. \& Gil LAForga, I. (2012): “Derivación sobre bases sintagmáticas en español”, en A. FÁbregas, E. FELÍU, J. MARTín \& J. PAZÓ (eds.), pp. 177-191. https://doi.org/10.15366/l.morfologia2012.010.

GAETA, L. (2006): “Lexical Integrity as a Constructional Strategy”, Lingue e Linguaggio V (I), pp. 67-82.

GonZÁLEZ GARCÍA, L. (1997): “Esbozo de una morfología funcional”, Moenia 3, pp. 5-49.

GonZÁlEz GARCíA, L. (2001): “Construcciones de relativo anómalas y despronominalización”, en A. VEIGA \& M. R. PÉREZ (eds.): Lengua española y estructuras gramaticales. Anexo 48 de Verba, Santiago de Compostela: Universidad de Santiago de Compostela, pp. 83-195.

GonZÁlez GARCíA, L. (2019a): “Clases y funciones en el ámbito morfológico”, Estudios de Lingüística de la Univsersidad de Alicante 32, pp. 179-193. https://doi.org/10.14198/ELUA2018.32.8.

GONZÁLEZ GARCÍA, L. (2019b): “Formación de palabras en español actual”, en R. GONZÁLEZ, I. OLZA \& O. LOUREDA (eds.): Lengua, cultura, discurso. Estudios ofrecidos al profesor Manuel Casado Velarde. Pamplona: EUNSA, pp. 631-652.

GonZÁlez OllÉ, F. \& CASAdo Velarde, M. (1992): “Formación de palabras”, en G. Holtus, M. Metzeltin \& C. Schмiтt (eds.): Lexikon der Romanistischen Linguistik. Tübingen: Niemeyer, vol. VI: 1, pp. 91-109.

GONZÁLEZ VERGARA, C. E. (1999): “La parasíntesis: una perspectiva funcionalista”, Onomázein 4, pp. 443-457.

GricE, H. P. (1975): “Logic and Conversation”, en P. Cole \& J. L. MorGan (eds.): Syntax and Semantics, Vol. 3, Speech Acts. New York: Academic Press, pp. 41-58.

HAOUET, L. (2000): En torno a la relación entre morfología y sintaxis: la formación de los parasintéticos en español. Tesis doctoral, Universidad Autónoma de Madrid. https://repositorio.uam.es/handle/10486/12047.

HERnANDo CuAdrado, L. A. (1999): “La parasíntesis en español”, Didáctica (Lengua y Literatura) 11, pp. 7794. 
HEYNA, F. (2012): Étude morpho-syntaxique des parasynthétiques. Les dérivés en dé- et en anti-. Bruxelles: De Boeck-Duculot. https://doi.org/10.3917/dbu.heyna.2012.01

IACOBINI, C. (2010): “Les verbes parasynthétiques: de l'expression de l'espace à l'expression de l'action”, De lingua Latina 3. http://www.paris-sorbonne.fr/IMG/pdf/Iacobini parasynthetiques.pdf.

KARI, E. E. (2015): "Parasynthesis in degema: simultaneous affixation or suffixation and concomitant prefixation?", Journal of the Linguistics Association of South African Development Community Universities (LASU) 4/2, pp. 8-23.

LÁZARo Mora, F. (1986): “Sobre la parasíntesis en español”, Dicenda 5, pp. 221-235.

Lieber, R. (2010): Introducing Morphology. Cambridge: Cambridge University Press. https://doi.org/10.1017/CB09780511808845.

LÜDTKE, J. (2005): “Probleme einer funktionellen romanischen Wortbildungslehre: Gibt es Parasynthese?”, en C. Kelling, J. MeinsChaefer \& K. Mutz (eds.): Morphologie und romanische Sprachwissenschaft. Konstanz: Fachbereich Sprachwissenschaft der Universität Konstanz, pp. 125-139. http://kops.unikonstanz.de/bitstream/handle/123456789/3731/AP_120.pdf.

MARQUETA GRACIA, B. (2018): "Prefijos preposicionales y compuestos con preposiciones: dos fenómenos independientes”, Lingüística en la red 16, pp. 1-24.

MARTín Vegas, R. A. (2005): “Segmentación morfemática o reanálisis? Formaciones con el sufijo -idad, *-abilidad, *-icidad, *-eidad...", Moenia 10, pp. 269-281.

Martinet, A. (1979): Grammaire fonctionnelle du français. Paris: Didier/Crédif.

MARTínEZ-ARbELAIZ, A. (2001): “La parasíntesis: ¿fenómeno morfológico o sintáctico?”, en M. GonZÁLEZ PEREIRA \& M. SOUTO GómEZ (eds.): Cuestiones conceptuales y metodológicas de la lingüística, Anexos de Moenia. Santiago de Compostela: Universidad, pp. 183-193.

$M D=$ Mundo DEPORTIVo: Hemeroteca. https://www.mundodeportivo.com/hemeroteca.

MELLONI, Ch. \& A. BISETTO (2010): “Parasynthetic compounds: Data and theory”, en S. SCALISE \& I. VOGEL (eds.): Cross-Disciplinary Issues in Compounding. Amsterdam/Philadelphia: John Benjamins, pp. 199217

Montero Curiel, M. L. (1999): La prefijación negativa en español. Anejos del Anuario de Estudios Filológicos. Cáceres: Universidad de Extremadura.

$N G L E=$ REAL ACADEMIA ESPAÑOLA y ASOCIACIÓN DE ACADEMIAS DE LA LENGUA ESPAÑOLA (2009): Nueva gramática de la lengua española. Morfología y sintaxis. Madrid: Espasa.

NTLLE = REAL ACADEMIA ESPAÑolA: Nuevo tesoro lexicográfico de la lengua española (NTLLE). http://ntlle.rae.es/ntlle/SrvltGUILoginNtlle.

PEnA SEIJAS, J. (1991): “La palabra: estructura y procesos morfológicos”, Verba 18, pp. 69-128.

PENA [SEIJAS], J. (1999): "Partes de la morfología. Unidades del análisis morfológico”, en I. BosQUE \& V. DEMONTE (dirs.), pp. 4305-4366.

Pena Seijas, J. (2003): "La relación derivativa”, Estudios de Lingüística de la Universidad de Alicante 17, pp. 505-517. https://doi.org/10.14198/ELUA2003.17.27.

PotTiER, B. (1962): Systématique des éléments de relation. Étude de morphosyntaxe structurale romane. Paris: Klincksieck.

RAE 1931 = REAL ACADEMIA ESPAÑOLA (1931): Gramática de la lengua española. Madrid: Espasa-Calpe.

RAE 1973 = REAL ACADEMIA ESPAÑOLA (1973): Esbozo de una Nueva Gramática de la lengua española. Madrid: 
Espasa.

RICHARD, J. (2017): “La parasynthèse (1). Définition et application au latin”, Folia Electronica Classica 33, pp. 1-26. http://bcs.fltr.ucl.ac.be/FE/33/Parasynthese1.pdf.

Rodríguez NAVAS, M. (1918): Diccionario general y técnico hispano-americano. Madrid: Cultura Hispanoamericana.

Rojo, G. (1994): “Estado actual y perspectivas de los estudios gramaticales de orientación funcionalista aplicados al español”, Verba 21, pp. 7-23.

SAUSSURE, F. de (1945 [1916]): Curso de Lingüística General, traducción, prólogo y notas de Amado Alonso. Buenos Aires: Losada.

SCALISE, S. (1984): Morfologia Lessicale. Padua: CLESP.

SCALISE, S. (1994): Morfologia. Bologna: Il Mulino.

SECo, R. (1975): Manual de gramatica española, Madrid: Aguilar.

SERRANO-DOLADER, D. (1995): Las formaciones parasintéticas en español. Madrid: Arco/Libros.

SERRANO-Dolader, D. (1999): “La derivación verbal y la parasíntesis”, en I. Bosque \& V. Demonte (dirs.), pp. 4683-4755.

SERRANo-Dolader, D. (2002): "Hacia una concepción no-discreta de algunas formaciones con anti- en español”, Revista Española de Lingüística 32,2, pp. 387-411.

SERRANO-Dolader, D. (2012a): "Sobre los adjetivos ¿parasintéticos? locativos (submarino, intramuscular, interdigital)”, en E. BERNAL, C. SINNER \& M. EMSEL (eds.): Tiempo y espacio en la formación de palabras del español. München: Peniope, pp. 65-78.

SERrano-Dolader, D. (2012b): “Sobre los compuestos (para)sintéticos ¿en español?”, en A. FÁBrEGAS, E. FELÍU, J. MARTín \& J. PAZó (eds.), pp. 427-442. https://doi.org/10.15366/l.morfologia2012.026.

SERrano-Dolader, D. (2013): “Hacia la delimitación del concepto de parasíntesis en composición”, en J. F. Val Álvaro, J. L. Mendívil, M. C. Horno, I. IbarrextXe, A. Hijazo, J. Simón \& I. Solano: De la unidad del lenguaje a la diversidad de las lenguas. Zaragoza: Universidad de Zaragoza, pp. 811-822.

Serrano-Dolader, D. (2015): “Parasynthesis in Romance”, en P. O. MÜller, I. OHNHEISER, S. OlSEN \& F. RAINER (eds.): Word-Formation. An International Handbook of the Languages of Europe, Vol. 1. Berlin: De Gruyter Mouton, pp. 524-536. https://doi.org/10.1515/9783110246254-031.

SERrano-Dolader, D. (2016): "Viejas y nuevas aproximaciones al concepto de parasíntesis", en C. Buenafuentes, G. Clavería \& I. Pujol (eds.): Cuestiones de morfología léxica. Madrid-Frankfurt am Main: Iberoamericana-Vervuert, pp. 9-34. https://doi.org/10.31819/9783954878567-002.

SERrano-Dolader, D. (2017): "La parasíntesis como proceso lexicogenético (no tan) peculiar”, en J. PenA (ed.): Procesos morfológicos. Zonas de interferencia, Anexo 76 de Verba. Santiago de Compostela: Universidad, pp. 49-76.

SPEnCER, A. (2005): "Word-Formation and Syntax", en P. ŠTEKAUER \& R. LiEBER (eds.): Handbook of WordFormation. Dordrecht: Springer, pp. 73-97. https://doi.org/10.1007/1-4020-3596-9 4.

STEHLÍK, P. (2013): “Algunos problemas del análisis de formaciones interfijadas y parasintéticas en español”, Romanica Olomucensia 25.2, pp. 151-159. https://doi.org/10.5507/ro.2013.018.

TOGEBY, K. (1951): Structure immanente de la langue française, Travaux du cercle linguistique de Copenhague, vol. VI. Copenhague: Nordisk Sprog- og Kulturforlag.

VARELA ORTEGA, S. (1990): Fundamentos de morfología. Madrid: Síntesis. 
VARELA ORTEGA, S. (2005): Morfología léxica: la formación de palabras. Madrid: Gredos.

VARELA ORTEGA, S. \& HAOUET, L. (2001): "For a morphological analysis in the privacy of the lexicon: prefixed verbs”, Cuadernos de lingüística del I. U. Ortega y Gasset 8, pp. 53-69.

ZACARÍAS PONCE DE LEÓN, R. (2016): Rivalidad entre esquemas de formación de palabras. México: UNAM.

\section{Notas}

${ }^{1}$ El más importante precursor es Butet de la Sarthe y sus composés-dérivés (Heyna 2012: 14).

${ }^{2}$ Darmesteter al lado de las formaciones vistas, que denominó parasynthèse de langage, identificó también otro tipo de parasíntesis, la parasynthèse d'idées o fausse parasynthèse, la cual "qualifie les adjectifs de type sous-marin, qui se caractérisent par le fait que leur sens se construit par rapport à la base substantivale, alors que sur le plan segmental, ils semblent être construits par préfixation sur une base adjectivale" (Heyna 2012: 21). Estas formaciones serán analizadas en $\S 3.1 .3 .1$.

3 Dice la RAE (1973: 170): “En la estructura de estas palabras, llamada parasíntesis, se dan de manera solidaria derivación y composición sin que la palabra central [... participe más de la una que de la otra."

${ }^{4}$ La vinculación entre preposiciones y prefijos (y no solo desde el punto de vista histórico o etimológico) no es exclusiva de las gramáticas tradicionales (Alemany Bolufer 1920, RAE 1931, RAE 1973; Vid. Felíu Arquiola 2003: 42-44) sino que se extiende también por otras corrientes lingüísticas hasta la actualidad (Pottier 1962, Martínez-Arbelaiz 2001, Lüdtke 2005, Melloni \& Bisetto 2010).

${ }^{5}$ Estas autoras mencionan dentro de este marco las propuestas de Booij (2007: 26) y Gaeta (2006). El análisis que este último hace del parasintético italiano terzomondale puede ser traducido a nuestro tercermundista, en el que confluirían las reglas $[\mathrm{A} \mathrm{N}]_{\mathrm{N}}$ (cf. quinta-esencia) y $[\mathrm{N}+i s t a]_{\mathrm{ADJ}}$ (cf. segregacion-ista). Booij señala el mismo proceso en el caso de adjetivos holandeses o ingleses en los que el prefijo negativo se aplica sobre bases positivas no existentes, fenómeno que ocurre también en español (imperdible, incansable). Traducido al castellano, Booij propone la regla [in[V-ble $\left.]_{A}\right]_{A}$, en la que se fusionarían [V-ble $]_{\mathrm{A}}$ (soporta-ble) e [in-A $]_{\mathrm{A}}$ (in-soportable).

${ }^{6}$ Evidentemente, no aparecen en el cuadro todas las formaciones parasintéticas mencionadas en estas obras. En aquellos casos más productivos (por ejemplo, verbos formados sobre el esquema en-ADJ-ecer) solo mencionamos alguna muestra significativa. Por otra parte, las formaciones incluidas en cada columna (especialmente en la $8^{\mathrm{a}}$ ) no son totalmente homogéneas en cuanto al procedimiento preciso que opera en la formación del tema de cada palabra (picapedrero $[\mathrm{V}+\mathrm{N}+\mathrm{Sf}]$, misacantano $[\mathrm{N}+\mathrm{V}+\mathrm{Sf}]$, ropavejero $[\mathrm{N}+\mathrm{Adj}+\mathrm{Sf}]$, etc.). Para nuestro propósito, el hecho determinante para incluir una palabra en esta categoría es la concurrencia de composición y derivación no analizables de manera secuencial.

7 No entramos en la cuestión, secundaria, de si -iz- es un sufijo o un interfijo (Vid. González García 2019a). En la tradición lingüística los elementos que preceden a los morfemas flexivos (y que, por tanto, se sitúan al final del tema) se denominan sufijos: -er $(0, a)$, -it(o, a). Por tanto, mantendremos esta denominación.

${ }^{8}$ Para resolver este problema, Serrano-Dolader en sus últimos trabajos (2017: 58) postula que en todos los casos la vocal temática es el morfema verbalizador, por lo que sugiere que en los conglomerados como -ecer o -izar, los segmentos ec- e -iz- no serían transcategorizadores.

9 Así se describe en las lenguas en las que se documenta este tipo de afijación: georgiano, coriaco (paleosiberiano), alemán (Pena Seijas 1991: 76), holandés, tagalo (Lieber 2010: 78), distintas lenguas africanas (Kari 2015: 11), etc.

${ }^{10}$ Por tanto, no hay morfo discontinuo en la mayoría de las propuestas que defienden este tipo de análisis: en Togeby (1951) en verbos como déchaîner, en Martinet (1979) ante adjetivos como imbattable (Vid. estas y otras propuestas similares en Heyna 2012: 36-41), en Bosque (1983) a propósito de embarcar (en- -ar), en Eguren (1991) para afear o en Zacarías Ponce de León (2016: 57-67) para aniñar (a- - ar) o enfriar (en- -ar). En todos estos casos los afijos que entran en juego son de diferente naturaleza, se trata de dos morfemas distintos: en dé- -er, en- -ar, a- -ar, el primero derivativo y el segundo un conglomerado formado por la vocal temática y un morfema flexivo; en el caso de Martinet (in--ble) nos hallamos ante dos afijos derivativos de valor y función bien diferenciados. La mera adjunción simultánea de dos afijos no implica automáticamente que se trate de un morfema discontinuo, como parece sugerir la NGLE (577-578), al hacer sinónimos los conceptos de parasíntesis y afijación discontinua. Por otra parte, como hemos intentado argumentar, el recurso a los morfos discontinuos refuerza la hipótesis de ramificación binaria, en lo que también discrepamos con la 
NGLE (“Conviene recordar que [...] la existencia de afijos discontinuos parece sugerir que la segmentación morfológica de las palabras no es siempre binaria", NGLE: 578). Finalmente, cabe señalar que otra representación binaria de los morfos discontinuo, de corte generativista, se puede ver en Eguren (1991: 488).

${ }^{11}$ El capítulo IV (Zacarías Ponce de León 2016: 57-67) está dedicado precisamente a la "Rivalidad entre los verbalizadores parasintéticos causativos". Obsérvese que, en nuestro planteamiento, de oposición binaria (lengua/habla), la norma coseriana (sistema/norma/habla, Coseriu 1973) recibe una atención secundaria. La norma actúa en un momento ulterior sancionando aquellas formaciones que, surgidas de un acto de habla, acabarán siendo aceptadas como normales por la comunidad. El cambio lingüístico (en este caso, la creación de una nueva unidad léxica) comienza, como señala Saussure (1945 [1916]: 64, 172-174) en un acto de habla. La lengua, ahora entendida como sistema, actúa ofreciendo el conjunto de posibilidades (cuyo producto son, en este caso, las palabras posibles) sobre el que actúa la norma, sancionando socialmente aquellas formaciones que triunfarán en una comunidad, las palabras realmente existentes (Coseriu: 1973: 78-79). El funcionamiento de la norma es, hasta cierto punto, impredecible: ¿qué principio ha determinado el distinto éxito, a lo largo de la historia del español, de las formas emblandecer, ablandecer y ablandar, existentes en el comienzo del idioma según atestigua el $C D H$ ). En este sentido, cabe destacar que muchas de las formaciones parasintéticas (o de otro tipo) creadas por los hablantes probablemente sean efímeras (¿cuál será el futuro de voces como sincorbatismo, ojiplático, concebollero y otras similares que se analizan en estas líneas?). Para el propósito de nuestro trabajo, sin embargo, esto es secundario, porque lo que nos interesa es el proceso en sí.

12 "Non vi è modo di suddividere il significato equamente tra la parte prefissale e la parte suffissale" (Scalise 1994: 58).

${ }^{13}$ Este análisis que defendemos para las formaciones regulares (en-_ec-, a-_iz-, etc.) no es aplicable a todas las combinaciones de doble afijación simultánea. En algunos casos menos regulares en los que entran en juego otros prefijos, con un significado diferenciado, sí puede defenderse un análisis parasintético. Pero siempre es necesario recurrir a la historia de cada palabra: por ejemplo, descuartizar, que el DCECH (s. v. cuarto) considera derivado de cuartizo, sí puede considerarse una formación parasintética creada sobre cuarto [[des+cuart+iz]-a-r] si atendemos a la documentación del $C D H$. En el mismo grupo podemos incluir desratizar e insonorizar (caso más problemático, pues el DLE considera que se trata de un derivado del adjetivo extremadamente infrecuente insonoro). Problemático es también el esquema re-_ec(er) de reblandecer y rejuvenecer, donde es difícil determinar si nos hallamos ante un prefijo reanalizable como intensificador (en este caso originaría una construcción parasintética) o bien se trata de otra variante del esquema (18). Con todo, las construcciones parasintéticas de este tipo son muy escasas. Desechadas las formas incluidas en las columnas 1 y 2, vemos que prácticamente no existen verbos parasintéticos en español. Más abajo (n. 33) comprobaremos que los verbos incluidos en la columna 9 tampoco cumplen los requisitos propios de la parasíntesis.

${ }^{14}$ Incluye Serrano-Dolader una cuarta clase de adjetivos, de oposición (anti-) o adhesión (pro-), como antifiebre, progubernamental, que, tras un detallado análisis, quedan excluidos de la lista de parasintéticos (defiende su carácter periférico en la transición gradual, no discreta, establecida entre la categoría de los prefijos y la de las preposiciones [Serrano-Dolader 1999: 4740 y 2002]). Como tampoco entran dentro de la definición que aquí defendemos para la parasíntesis, prescindiremos de su análisis en este trabajo (por ejemplo, antifiebre carece de sufijación derivativa). Estas formaciones se tratan con detalle en Felíu Arquiola (2003).

${ }^{15}$ Darmesteter justifica de la siguiente manera el proceso de formación: "Comment la combinaison de marin «relatif à la mer» avec sous arrive-t-elle à signifier «relatif à ce qui est sous la mer»? C'est que, dans la combinaison sous-marin, l'adjectif se décompose logiquement, de telle façon que le mot mer qui se trouve contenu dans l'idée de marin devient le régime de la préposition sous" (Darmesteter 1895: 25).

${ }^{16}$ La oposición ambigüedad (u homonimia) estructural frente a indeterminación constituye un clásico tema de discusión en el análisis sintáctico. Piénsese en secuencias como María y Juan están casados. Un análisis transformacional implicaría una ambigüedad estructural, es decir, la existencia de dos estructuras diferentes para las dos interpretaciones posibles 'María está casada con Juan' y ‘María está casada y Juan está casado'. En el análisis funcionalista habrá indeterminación (una única estructura, en la que el sujeto es una construcción coordinativa, susceptible de varias interpretaciones o sentidos). La ambigüedad estructural, frecuente en sintaxis (llenar el vaso de agua), también ha sido identificada en el nivel morfológico: "Consideremos el adjetivo inmovilizable (ejemplo de B. Tranel). Dicho adjetivo tiene dos significados: «que puede ser inmovilizado» 0 «que no puede ser movilizado» [... ]. El orden en que efectuemos la segmentación basta para dar cuenta de esta ambigüedad. En el primer caso analizaríamos inmovilizable como ((in-(móvil-) ADJ -iza-)v)-ble)ADJ [sic], y en el segundo, como (in-(((móvil-) $)_{A D}$ iza-) $\left.\left.)_{V}-b l e\right)\right)_{A D}$ " (Bosque 1983: 131. También Varela Ortega 1990: 21 y Pena Seijas 1999: 4314). No creemos que la ambigüedad estructural tenga mucha relevancia en el ámbito morfológico más allá de creaciones de laboratorio de las que tanto gustaba la GGT (señala la NGLE: 1.5.ñ: "la doble segmentación es excepcional en la morfología del español"). La norma suele dar preferencia a uno solo de los significados posibles (es el 
caso de inutilizable, manejado en las referencias anteriores, cuyo único significado se puede comprobar en el DLE: s. v.). Este hecho se puede ilustrar (a modo de anécdota) con una escena del conocido programa televisivo Los Simpson (Temporada 12, Capitulo 18): ante una bombona que acaba de explotar, sobre la que luce el letrero inflammable, el doctor Nick Riviera, de origen hispano, cuyo dominio del inglés no supera su ineptitud profesional, se queja: «'Inflammable' means ‘flammable’? What a country!» (https://www.youtube.com/watch?v=Q8mD2hsxrhQ). Es evidente que el Dr. Riviera segmenta, erróneamente, [in-[flamma-ble]] ('no inflamable') en lugar del correcto [[in-flamma]-ble] ('que se puede inflamar').

17 El CDH localiza la primera documentación del lema madridista en 1935 en tanto que antimadridista se retrasa hasta 1986.

${ }^{18} \mathrm{El} \mathrm{CDH}$ es tajante al respecto. La consulta del lema prerrafaelista arroja 63 casos desde 1896, en tanto que rafaelista solo ofrece una muestra efímera (José María de Cossío [1966]: Los mejores toreros de la historia), relativa al torero Rafael Gómez El Gallo: “Don Pío, el portavoz del gallismo rafaelista”.

${ }^{19}$ El CDH (lema supersónico) muestra 79 concordancias, la más antigua de 1951. La Hemeroteca de Mundo deportivo (MD) adelanta la primera documentación cinco años (17/10/1946). El DLE admitió la entrada en su edición de 1956. Por su parte, sónico es un tecnicismo posterior, incorporado en el DLE en la edición de 2001 (con anterioridad, fue incluido en el Diccionario Manual de 1985 y 1989).

${ }^{20}$ Este principio fue utilizado por Booij (2007) para justificar la no existencia de palabras posibles como faced o eyed, segundo componente de los parasintéticos blue-eyed o red-faced. La Non-Redundancy Constraint, limitada innecesariamente por sus autores a los participios de pasado en inglés, enlaza con la máxima de cantidad de Grice (1975), en el sentido de que no debemos proporcionar más información de la requerida. Así, señala Booij (2007: 218): “It is expected that human beings have a face, and hence it does not seem to make much sense from a pragmatic point of view to say My husband is faced". Ideas semejantes sobre las causas que limitan la existencia de palabras posibles se pueden contrastar en Corbin (1997).

${ }^{21}$ A partir de este momento utilizaremos el símbolo ${ }^{\times}$para aludir a palabras posibles, bien formadas, pero no existentes en un momento determinado en una lengua ( ${ }^{\times}$alámbrico), por oposición a *, que reservaremos para las palabras no posibles de acuerdo con las RFP (*inalambre).

${ }^{22}$ EI CORDE ofrece para inalámbrico 23 muestras, las más antiguas recogen textos escritos en Perú y Colombia entre 1908 y 1930 (las primeras documentaciones parecen corresponder al año 1914). La muestra española más antigua es de 1924, si bien la Hemeroteca Digital (BNE) permite adelantar esa fecha a 1907 en la revista Unión Ibero-Americana. El primer diccionario que recoge este término es el de Rodríguez Navas (1918) (NTLLE: s. v. "Sin alambres o sin hilos transmisores. | Se aplica al telégrafo de Marconi”). Por su parte, alámbrico aparece en tres documentos posteriores (9 casos), todos españoles, el más antiguo de 1929. El hecho de que alámbrico se utilice en menor medida y principalmente en textos técnicos ocasiona -como se ha señalado- que no figure en los diccionarios recopilados en el Nuevo Tesoro Lexicográfico ni en el DLE.

23 "La parasíntesis no debe entenderse como un procedimiento lexicogenético diferenciado sino como un proceso lexicogenético particularizado por el hecho de combinar solidariamente procedimientos diversos" (Serrano-Dolader 2017: 53, cursiva en el original). La misma idea se repite en Serrano-Dolader (2013: 814).

${ }^{24}$ Lo cual es frecuente en los complejos morfológicos -bilidad e -ización: accidentabilidad (DLE 2001), jugabilidad (DLE 2014), empleabilidad (DLE 2014), ocupabilidad, mundialización (DLE 2014), tercerización (DLE 2014), semaforización, dieselización, eurización, salarización, adolescentalización, elitización, disneyización, etc. Obsérvese que en estos casos podríamos hablar de parasíntesis por doble sufijación simultánea y no sucesiva. lacobini (2010: 6) comprobó que este proceso de documentación de un derivado antes que su base ya se producía en latín (por ej., egurgito / gurgito). Por otra parte, la doble adjunción de afijos simultáneos se produce también en la interfijación (Stehlík 2013), ejs. pint-arr-aj-a-r, vent-arrón ('ventarro, ’ventón).

25 “Aclaro que la palabra sacapuntero, que acabo de inventar, entrará en el diccionario de la RAE para definir al periodista que, obligado por la necesidad, se especializa en sacarle punta a todo y a nada" (https://www.lavozdegalicia.es $[20 / 09 / 2018 /])$.

26 "Es por todos sabidos [sic] que [...] es un integrista sincebollero. Algunos, incluso, afirman que lo han visto desmenuzando tortillas para comprobar su sincebollitud" (https://twitter.com/ [26/02/2019]).

27 "Cada cual es como le hacen y cada uno con su cadaunada" (CORDE: Unamuno, Amor y pedagogía).

28 Sinhilismo y sinhilista son parasintéticos antiguos utilizados para referirse, respectivamente, a la radio y a los radioaficionados. En la Hemeroteca Digital (BNE) se documentan 140 muestras, la mayoría entre 1924 y 1935 . Obsérvese la concomitancia con el parasintético inalámbrico, de mayor fortuna. 
${ }^{29}$ Marqueta Gracia (2018: 10) alude a estas construcciones con el nombre de lexicalización de sintagmas. El proceso que lleva de la frase preposicional a la palabra compuesta se puede rastrear en la unidad sin techo, frase todavía no fijada totalmente, que en el DLE (s. v. techo) aparece como locución adjetiva, usada también como locución sustantiva (los sin techo). Con todo, en la prensa es frecuente encontrar la forma unificada ortográficamente, por lo que la Fundación Fundéu recomienda: «La forma sintecho, escrita en una sola palabra, es preferible a la opción sin techo, en dos palabras, para aludir a aquella persona que carece de vivienda y, generalmente, de cualquier medio de vida'» (Fundéu: https://www.fundeu.es/recomendacion/sintecho-en-una-sola-palabra-564/[31/01/2019]). Sobre este sustantivo sintecho se ha formado el derivado sintechismo, si bien, la Fundéu observa que "con este sentido [... ] no cuenta con un uso tan extendido como sinhogarismo" (https://www.fundeu.es/recomendacion/sinhogarismo-sin-hogar-sintecho-sintechismo [30/09/2019]. En nuestra terminología, sintechismo será considerada forma derivada del compuesto sintecho, en tanto que sinhogarismo se analizará como parasintética ( $\operatorname{sin+hogar+ismo),~pues~su~base~es~una~construcción~sintáctica~(la~frase~}$ preposicional sin hogar). Obsérvese, en todo caso, que el proceso de lexicalización de sintecho todavía no ha concluido, como muestra la invariabilidad flexiva (plural los sintecho), por oposición a cadenas cuya fusión mayor ha originado sustantivos prototípicos (cfr. el sinvergüenza, pl. los sinvergüenzas).

$3^{30}$ Es discutible que las cadenas agua bendita, cuenta corriente o tercer mundo sean palabras compuestas. En todos los casos el adjetivo es un restrictor que se añade para acotar la significación del sustantivo: agua bendita / mineral / clorada / contaminada; cuenta corriente / de crédito / personal. Primer / tercer mundo son paralelos a primera / tercera / cuarta edad 'centenaria'. Con todo, todas esas formas figuran en el DLE como sustantivos femeninos por lo que, desde el punto de vista normativo, sí serían derivados de compuestos. Ahora bien, el grado de fijación de estas formas recomienda más bien incluirlas en el grupo de las locuciones sustantivas (observemos que, de admitir plural, este se repite en ambos constituyentes: las cuentas corrientes). El problema estriba en que la RAE restringe extraordinariamente la categoría de locución sustantiva (frente a loc. adj., loc. adv., loc. verb., etc.), por lo que tanto los nombres compuestos como este tipo de locuciones figuran bajo la misma abreviatura (f., m.), no sin cierta contradicción pues estas formas figuran en la parte del artículo lexicográfico destinada a las formas complejas, en concreto a las "combinaciones estables en que un sustantivo va acompañado por un elemento que desempeña una función adjetiva respecto a él” (DLE: XLIV), definición que parece encajar mejor en la de locución que en la de sustantivo.

${ }^{31}$ Felíu Arquiola \& Gil Laforga (2012) observan como este fenómeno de "derivación sobre bases sintagmáticas" (con el que evitan mencionar términos como locución, compuesto sintagmático, sintagma libre, etc.) se produce ante todo tipo de combinaciones: desde las más fijadas (en las que se produce un reanálisis sintáctico y ausencia de composicionalidad semántica) hasta las más libres (ausencia de reanálisis sintáctico y ausencia de restricciones léxicas). Es más, observan "en contra [de] lo que parecía esperable, los casos que hemos documentado en los que la base no se encuentra reanalizada (...) superan a aquellos en los que sí lo está" (2012: 183). Con todo, señalan la prevalencia de aquellos casos en los que, si bien nos hallamos ante unidades sintácticas que se comportan como sintagmas libres, sin embargo, están implicadas ciertas restricciones léxicas. Se trata de "combinaciones léxicas restringidas frecuentes y preferentes" (2012: 184): barriobajero, guerracivilista, cuentacorrentista, aguabenditera, malgeniado, versolibrismo, etc.

${ }^{32}$ En todo caso, en ambas palabras falta sufijo derivativo, por lo que no entran en nuestra categoría de palabras con composición y sufijación simultáneas. Se trata de palabras con tema compuesto, como maniatar o ensimismar.

33 Generalmente se hacen sinónimos tema complejo y derivado, pero creemos que entre ambos hay una diferencia de perspectiva: la denominación tema complejo implica un punto de vista estático, en tanto que tema derivado alude a un proceso (ignición tiene un tema complejo, pero no es una palabra derivada por carecer de verbo base; medición, por el contrario, tiene tema complejo y además es derivada; el verbo salar tiene tema simple pero es derivada).

34 “Dep. En alpinismo, montaña de 8000 m o más de altura" (DLE: s. v.).

35 Este principio entronca con la Hipótesis de la integridad léxica, la cual establece que "syntactic rules or principles have no access to internal word structure and hence cannot create words" (Spencer 2005: 73).

${ }^{36}$ Un buen ejemplo de las diferencias existentes entre una lingüística de la lengua y una lingüística del habla nos la proporcionan las oraciones de relativo (González García 2001). La no planificación propia del habla lleva a crear una construcción como Es una persona que, si mal no recuerdo, coincidí con ella varias veces, en lugar de la cual la lengua prefiere Es una persona con la que, si mal no recuerdo, coincidí varias veces.

37 En tal caso se produce una recategorización. Es el caso de -ería: En principio -er(o, a) e -ía eran sufijos sucesivos (trapacero > trapacería, majadero > majadería). Sin embargo, en la actualidad -ería puede actuar como un sufijo único: tonto > tontería, bobo > bobería (Campos Souto 2012). 